\title{
The Analysis of Secondary Motion and Lubrication Performance of Piston considering the Piston Skirt Profile
}

\author{
Yanjun Lu, ${ }^{1,2}$ Sha Li, ${ }^{1,2}$ Peng Wang, ${ }^{1,2}$ Cheng Liu, ${ }^{1,2}$ \\ Yongfang Zhang $\left(1,,^{3}\right.$ and Norbert Müller ${ }^{4}$ \\ ${ }^{1}$ School of Mechanical and Precision Instrument Engineering, Xian University of Technology, Xian 710048, China \\ ${ }^{2}$ State Key Laboratory of Digital Manufacturing Equipment and Technology, Huazhong University of Science and Technology, \\ Wuhan 430074, China \\ ${ }^{3}$ School of Printing, Packaging Engineering and Digital Media Technology, Xian University of Technology, Xian 710048, China \\ ${ }^{4}$ College of Engineering, Michigan State University, East Lansing, MI 48824, USA
}

Correspondence should be addressed to Yongfang Zhang; zhangyf@xaut.edu.cn

Received 17 July 2017; Revised 26 January 2018; Accepted 8 February 2018; Published 27 March 2018

Academic Editor: Giorgio Dalpiaz

Copyright (C) 2018 Yanjun Lu et al. This is an open access article distributed under the Creative Commons Attribution License, which permits unrestricted use, distribution, and reproduction in any medium, provided the original work is properly cited.

\begin{abstract}
The work performance of piston-cylinder liner system is affected by the lubrication condition and the secondary motion of the piston. Therefore, more and more attention has been paid to the secondary motion and lubrication of the piston. In this paper, the Jakobson-Floberg-Olsson (JFO) boundary condition is employed to describe the rupture and reformation of oil film. The average Reynolds equation of skirt lubrication is solved by the finite difference method (FDM). The secondary motion of pistonconnecting rod system is modeled; the trajectory of the piston is calculated by the Runge-Kutta method. By considering the inertia of the connecting rod, the influence of the longitudinal and horizontal profiles of piston skirt, the offset of the piston pin, and the thermal deformation on the secondary motion and lubrication performance is investigated. The parabolic longitudinal profile, the smaller top radial reduction and ellipticities of the middle-convex piston, and the bigger bottom radial reduction and ellipticities can effectively reduce the secondary displacement and velocity, the skirt thrust, friction, and the friction power loss. The results show that the connecting rod inertia, piston skirt profile, and thermal deformation have important influence on secondary motion and lubrication performance of the piston.
\end{abstract}

\section{Introduction}

The piston-cylinder liner system is a key subsystem of the internal combustion engines (ICEs); the performance of the piston-cylinder liner system influences the efficiency and performance of ICEs. The work performance of piston-cylinder liner system is affected by the lubrication condition and the secondary motion of the piston. Therefore, more and more attention has been paid to the piston skirt lubrication and the secondary motion of the piston by many scholars recently [1-6]. Meng et al. [7] introduced the oil film inertia force effects to the Reynolds lubrication equation; the effects of oil film inertia on film pressure, hydrodynamic friction force, and transverse displacement were investigated. A nonlinear model of the piston considering the reciprocating, lateral, and rotational degree of freedom was established by Tan and
Ripin [8]. In their work, the piston secondary motion and the induced vibration behavior were studied; the proposed model was validated by the experimental data. Tan and Ripin [9] identified the intermittent transient contact of the piston skirt with the cylinder liner by measuring the tilting angle and secondary displacement. The impacting force was computed from the equation of motion and the frictional force ratio of the total friction force and torque was obtained. Murakami et al. [10] proposed a piston secondary motion analysis method coupling the structure analysis and the multibody dynamics analysis. The presented method was verified by comparing the numerical results with the measurement data of the piston skirt stress, secondary motion, and the vibrational acceleration produced on the cylinder. Besides the above works, more researches on the piston secondary motion have been carried out by taking some factors into 
consideration, such as surface roughness and lubrication condition. Meng et al. [11] investigated the influence of cylinder vibration on the lateral motion and tribological performances of the piston. The fluctuations of the cylinder vibration can be reduced by increasing mass, stiffness, and damping of the cylinder. Narayan [12] implemented a modeling of the piston secondary motion. The dynamic characteristics of the part of piston skirt and cylinder liner were analyzed, and the proposed model was validated by comparing the simulated results with the experimental data. Obert et al. [13] developed a reciprocating model test to investigate the influence of the temperature and oil supply on the tribological behavior of the piston ring-cylinder liner contacts. The real engine situation at fired top dead center was simulated by carefully adjusting the friction, scuffing, wear, oil supply, and temperature. Mazouzi et al. [14] presented a numerical secondary motion model to investigate the influence of the piston design parameters on the dynamic characteristics of a piston-cylinder contact. In their work, it was verified that the modification of clearance of the piston skirt-liner system and the axial location of piston pin can reduce the friction and piston slap. Fang et al. [15] modeled the piston skirt-liner lubrication and crank-rod-piston multibody system by taking the microgrooves on the piston skirt surface. Based on the presented model, the tribodynamic performance of the piston with skirt surface grooves was obtained and analyzed.

Regarding the influencing factors, the piston skirt profile has extreme significance for the secondary motion of the piston. Hence, the study of the effects of the piston skirt profile on the secondary motion and piston dynamics is essential. Littlefair et al. [16] analyzed the piston dynamics, thermoelastic distortion, and transient elastohydrodynamics of the lightweight piston with preferentially compliant short partial skirt. The greater entrainment wedge at bottom skirt and better conforming contact geometry at top skirt were achieved, and therefore, the load-carrying capacity was improved and the friction was reduced. McFadden and Turnbull [17] presented a model of the interface between a barrelled piston skirt and cylinder. In their work, the secondary motion and the pressure distribution of the oil film for changing the skirt profile were investigated. The research revealed that the wear of the cylinder arising from the rotation of the piston can be decreased by appropriate positioning of piston skirt. Gunelsu and Akalin [18] developed a dynamics model to investigate the secondary motion of piston for the different radius of curvature around the bulge of the barrel, the ellipse, and the aspect ratio. The secondary motion and frictional performance of the piston with the barrel and elliptical form of the skirt were analyzed. The results showed that the frictional performance can be improved via optimizing the piston skirt profiles. He et al. [19] established a numerical model of coupling lubrication and dynamic motion. The effects of the piston skirt parameters on dynamic performance were investigated, including the offset of piston pin, length of piston skirt, curvature parameter, and ellipticity. Furthermore, an asymmetrical skirt profile was proposed to reduce the thrust force on the liner. In order to investigate the influence of the design parameters of the piston skirt on the slap noise and the lubrication performance, the lubrication model of piston skirt-liner system and the dynamics model of multibody system were coupled by Zhao et al. [20].

Apart from the piston skirt profiles, the influence of the connecting rod inertia on lubrication performance of the piston skirt-liner system cannot be neglected. Therefore, more detailed dynamic analyses of the secondary motion by considering the inertia of the connecting rod were conducted [21-25]. Zhang et al. [21] developed a mathematical model of piston-connecting-rod-crankshaft system. Based on the coupling model of the secondary motion and the fluid dynamic lubrication, the influence of the variation in the system inertia on the piston secondary motion and the piston side force was investigated. The center-of-mass position was confirmed to be significant for the design of the connecting rod. Meng et al. [22, 23] conducted a numerical analysis of the piston dynamics, the oil film, and the friction loss of the piston skirt-liner system by taking the connecting rod inertia into consideration. The numerical results revealed that the influence of the connecting rod inertia on the side force, the oil film thickness, the frictional force, and the piston dynamics cannot be ignored, in particular at high speed. Furthermore, Meng et al. [24] presented a transient tribodynamic model by coupling the tribological performance and the dynamic characteristics of the piston skirt-liner system. By considering the angular acceleration of the crankshaft and the transient variable engine speeds, the secondary motion of the piston and engine performance were investigated. Zhu et al. [25] calculated the stress distribution of the connecting rod with consideration of the film lubrication or not. The minimum oil film thickness and maximum oil film pressure were calculated by the Reynolds equation. The results showed that the stress concentration can be reduced using smoother rounded fillet and longer fillet radius.

The thermal deformation is also an important influencing factor of the piston secondary motion and frictional characteristics. Therefore, the thermal deformation was increasingly introduced to relevant studies of the lubrication performance of the piston skirt. Pelosi and Ivantysynova [26] built a fully coupled simulation model for the piston/cylinder interface of axial piston machines and validated the model by comparing the prediction values with measurements of the fluid film boundary temperature distribution. The influence of the heat transfer and solids-induced thermal elastic deformation on the piston skirt-cylinder lubricating interface behavior was analyzed. Ning et al. [27] built a comprehensive lubrication model of the piston skirt-liner system. By considering the thermal and the elastic deformations of the piston skirt and the cylinder liner, the piston secondary motion was investigated.

The above-mentioned researches were carried out based on the Reynolds boundary. It is reasonable on the rupture boundary of oil film, but not on the reformation boundary. Jacoboson et al. $[28,29]$ presented the boundary conditions of conservation of mass on rupture and reformation boundaries of oil film, that is, JFO boundary condition. Since then, JFO boundary condition was considered as important factor in the investigation of the tribological properties. Zhao et al. [30] investigated the cavitation effects on the dynamic axial 


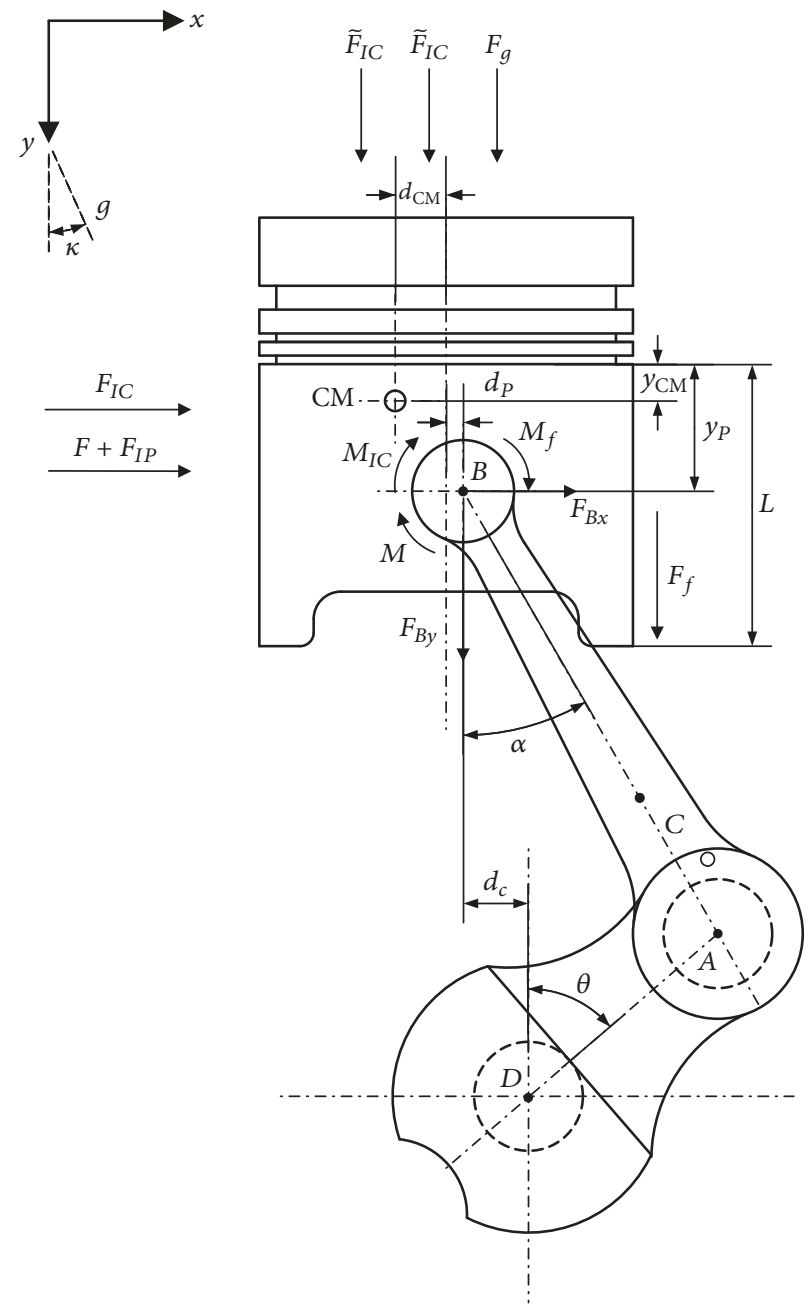

FIGURE 1: Geometrical model of piston-connecting rod mechanism.

stiffness and damping coefficients of spiral-groove rotary seals for the Reynolds and JFO boundary conditions. By contrasting the theoretical value with the experimental data, the verification result was obtained that computation values of JFO boundary condition were in better agreement with the experimental values than the values using the Reynolds model. Kango et al. [31] conducted a mathematical model to investigate the influence of the surface microtexture on the performance parameters of the bearing by JFO boundary condition. The realistic results can be obtained based on JFO boundary condition in comparison to the Reynolds boundary condition. Liu et al. [32] investigated the influence of the cylinder liner dimples on the lubrication performance of the compression ring-cylinder liner system based on JFO boundary condition. For different dimple area density, radius, and depth, the minimum oil film thickness and friction force were compared and analyzed under the engine-like conditions. The results showed that the spherical dimples can improve the tribological performance.

In this paper, the average Reynolds equation of the piston skirt lubrication is solved by FDM, and the secondary motion trajectory of the piston is calculated by the Runge-Kutta method. The difference of the secondary motion of the piston under JFO and the Reynolds boundary conditions is significant. In order to approach the actual working condition, JFO boundary condition is employed, and the variable $\phi$ and cavitation index $F$ are introduced to describe the full and rupture areas of oil film. By considering the connecting rod inertia, the effects of the longitudinal profiles of the piston skirt, the horizontal profiles, the offset of the piston pin, and the thermal deformation on the secondary motion and lubrication performance are investigated.

\section{Secondary Motion Model}

The piston makes reciprocating movement along cylinder liner; the crankshaft makes nonuniform rotation caused by piston. Figure 1 shows the geometrical model of pistonconnecting rod mechanism.

In Figure $1, F_{g}$ is the thrust of the gas on the top surface of the piston, $\widetilde{F}_{I C}$ and $\widetilde{F}_{I P}$ are the inertia forces of the piston and piston pin caused by reciprocating motion of piston, respectively, $F_{I C}, F_{I P}$, and $M_{I P}$ are the inertia forces of piston, piston pin, and the inertia moment of piston caused by the 
secondary motion of piston, respectively, $F_{t}$ and $M_{t}$ are the total lateral thrust force and lateral thrust moment of piston skirt, respectively, $F_{f}$ and $M_{f}$ are the friction and friction torque of piston skirt, respectively, $F_{B X}$ and $F_{B Y}$ are the forces of connecting rod acting on piston in the $x$ and $y$ directions, respectively, $g$ is the gravitational acceleration, $\kappa$ is the angle between gravity direction and $y$-axis, $d_{\mathrm{CM}}$ and $y_{\mathrm{CM}}$ are the distances from center of mass of piston to center line of piston and to top skirt, respectively, $d_{P}$ and $y_{P}$ are the distances from center of piston pin hole to center line of piston and to top skirt, respectively, $L$ is the length of the piston skirt, and $\alpha$ is the angle between the connecting rod and the center line of piston.

According to Figure 1, the force equation and moment equation of piston are established

$$
F_{t}+F_{I C}+F_{I P}+F_{B X}+m_{p} g \sin \kappa+m_{\text {pin }} g \sin \kappa=0,
$$

where $m_{p}$ and $m_{\text {pin }}$ are the mass of piston and piston pin, respectively.

$$
\begin{aligned}
& F_{g}+F_{f}+\widetilde{F}_{I C}+\widetilde{F}_{I P}+F_{B Y}+m_{p} g \cos \kappa \\
& \quad+m_{\mathrm{pin}} g \cos \kappa=0 \\
& M_{t}+M_{f}+M_{I C}-F_{g} d_{p}-m_{p} g \cos \kappa\left(d_{\mathrm{CM}}+d_{p}\right) \\
& \quad+m_{p} g \sin \kappa\left(y_{P}-y_{\mathrm{CM}}\right)+F_{I C}\left(y_{P}-y_{\mathrm{CM}}\right) \\
& \quad-\widetilde{F}_{I C}\left(d_{\mathrm{CM}}+d_{p}\right)=0 .
\end{aligned}
$$

The angle $\alpha$ between the center line of piston and the connecting rod is

$\alpha$

$$
=\tan ^{-1}\left(\left(d_{c}+e_{c} \sin \theta\right) \times\left[l_{\mathrm{cr}}^{2}-\left(d_{c}+e_{c} \sin \theta\right)^{2}\right]^{-0.5}\right),
$$

where $e_{c}$ is the length of the crankshaft, $d_{c}$ is the eccentricity of the centers of crankshaft and piston pin, and $\theta$ is the crank angle.

The inertia forces of piston and piston pin caused by reciprocating motion of piston are

$$
\begin{aligned}
& \widetilde{F}_{I C}=-m_{p} \ddot{y}_{B} \\
& \widetilde{F}_{I P}=-m_{\mathrm{pin}} \ddot{y}_{B},
\end{aligned}
$$

where $\ddot{y}_{B}$ is the acceleration of the reciprocating motion of piston.

As shown in Figure 2, the piston swings around the center of pin hole between the major thrust side (the side acted upon by the expansion thrust, $\varphi=0$ ) and the minor thrust side (the side acted upon by the compression thrust, $\varphi=\pi$ ). In order to describe the motion of the piston, the displacement $e_{t}$ of top skirt and displacement $e_{b}$ of bottom skirt are introduced to express the displacement, velocity, and tilting angle of piston secondary motion. In Figure 2, $\varphi$ is the circumferential coordinate of piston, $\varphi_{l}$ is the loading angle of piston skirt, $\gamma$ is the tilting angle of piston around center of pin, and $R$ is the radius of piston.

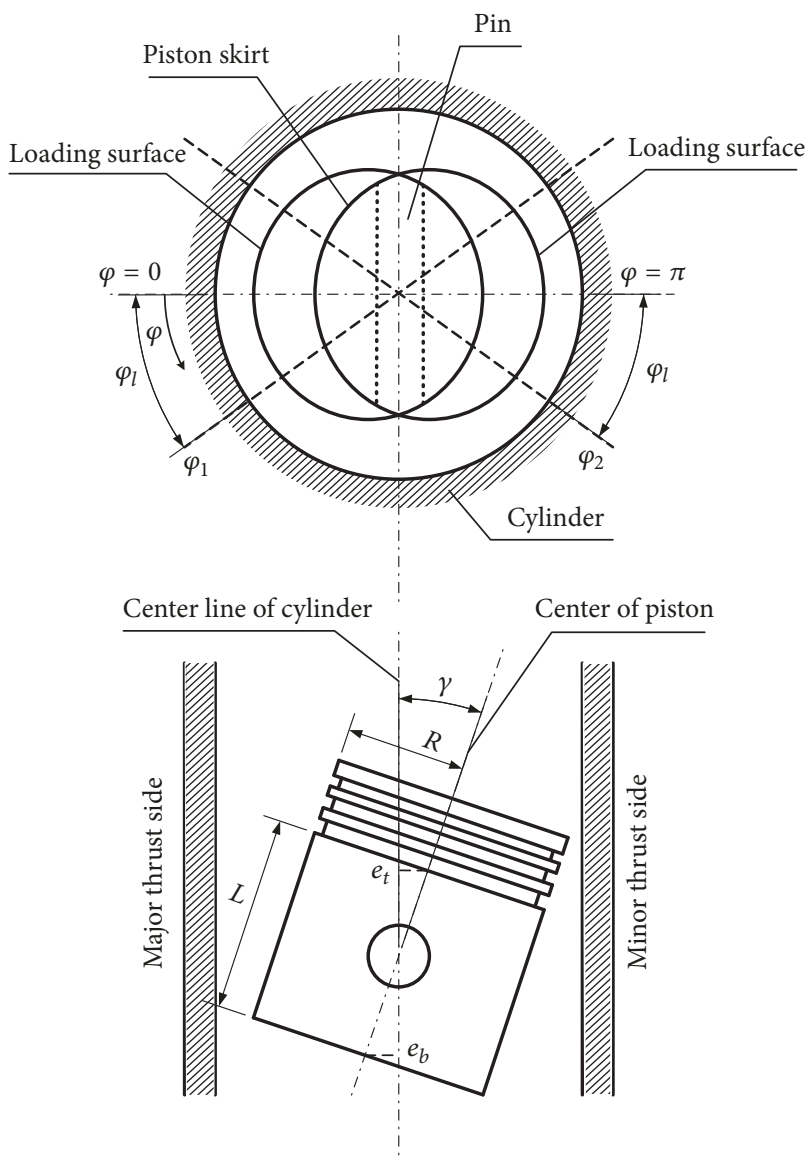

FIGURE 2: Schematic diagram of the piston-cylinder system.

The inertia forces of piston and piston pin and the inertia moment of piston caused by secondary motion are, respectively,

$$
F_{I C}=-m_{p}\left[\ddot{e}_{t}+\frac{y_{\mathrm{CM}}}{L}\left(\ddot{e}_{b}-\ddot{e}_{t}\right)\right],
$$

where $\ddot{e}_{b}, \ddot{e}_{t}$ are the acceleration values of the top skirt and bottom skirt.

$$
M_{I C}=-\frac{I_{p}\left(\ddot{e}_{t}-\ddot{e}_{b}\right)}{L},
$$

where $I_{p}$ is the inertia moment of piston around center of pin.

$$
F_{I P}=-m_{\mathrm{pin}}\left[\ddot{e}_{t}+\frac{y_{P}}{L}\left(\ddot{e}_{b}-\ddot{e}_{t}\right)\right] .
$$

By considering the inertia of connecting rod, the equilibrium equation of connecting rod is obtained.

$$
\begin{aligned}
& F_{A X}-F_{B X}+m_{\mathrm{cr}} g \sin \kappa-m_{\mathrm{cr}} \ddot{x}_{\mathrm{cr}}=0 \\
& F_{A Y}-F_{B Y}+m_{\mathrm{cr}} g \cos \kappa-m_{\mathrm{cr}} \ddot{y}_{\mathrm{cr}}=0,
\end{aligned}
$$

where $F_{A X}$ and $F_{A Y}$ are the component forces caused by the crank acting on the connecting rod in the $x$ and $y$ directions, respectively, $m_{\mathrm{cr}}$ is the mass of the connecting rod, and $\ddot{x}_{\mathrm{cr}}$ 
and $\ddot{y}_{\mathrm{cr}}$ are the components of acceleration of center of mass of the connecting rod in the $x$ and $y$ directions, respectively. is

The moment equilibrium equation of the connecting rod

$$
\begin{aligned}
& -F_{B X}(1-j) l_{\mathrm{cr}} \cos \alpha-F_{A X} j l_{\mathrm{cr}} \cos \alpha \\
& \quad+F_{B Y}(1-j) l_{\mathrm{cr}} \sin \alpha+F_{A Y} j l_{\mathrm{cr}} \sin \alpha-\ddot{\alpha} I_{\mathrm{cr}}=0,
\end{aligned}
$$

where $I_{\mathrm{cr}}$ is the moment of the connecting rod and $j$ is the ratio of distances from center of mass and big side to length of connecting rod, as follows:

$$
j=\frac{l_{A C}}{l_{A B}} .
$$

According to the equilibrium equation of force and moment of the piston and connecting rod, the equations are written as follows:

$$
\left[\begin{array}{ll}
A_{11} & A_{12} \\
A_{21} & A_{22}
\end{array}\right]\left[\begin{array}{l}
\ddot{e}_{t} \\
\ddot{e}_{b}
\end{array}\right]=\left[\begin{array}{c}
F_{s}+F_{s s}+F_{t} \\
M_{s}+M_{f}+M_{t}
\end{array}\right],
$$

where $M_{t}$ is the lateral thrust moment of piston skirt, $A_{11}$, $A_{12}, A_{21}$, and $A_{22}$ are relevant coefficients, $F_{t}$ is the lateral thrust force of piston skirt, $F_{s}$ and $M_{s}$ are the physical quantities of the parameters of the piston structure, and $F_{s s}$ is the physical quantity of the parameters of the connecting rod; the expressions are as follows:

$$
\begin{aligned}
A_{11} & =m_{\mathrm{pin}}\left(1-\frac{y_{P}}{L}\right)+m_{p}\left(1-\frac{y_{\mathrm{CM}}}{L}\right)+j^{2} m_{\mathrm{cr}}(1 \\
& \left.-\frac{y_{P}}{L}\right) \\
A_{12} & =m_{\mathrm{pin}} \frac{y_{P}}{L}+m_{p} \frac{y_{\mathrm{CM}}}{L}+j^{2} m_{\mathrm{cr}} \frac{y_{P}}{L} \\
A_{21} & =m_{p}\left(1-\frac{y_{\mathrm{CM}}}{L}\right)\left(y_{P}-y_{\mathrm{CM}}\right)+\frac{I_{p}}{L} \\
A_{22} & =m_{p}\left(y_{P}-y_{\mathrm{CM}}\right) \frac{y_{\mathrm{CM}}}{L}-\frac{I_{p}}{L} \\
F_{s}= & \left(-F_{g}-F_{f}-\widetilde{F}_{I C}-\widetilde{F}_{I P}-m_{p} g \cos \kappa\right. \\
& \left.-m_{\mathrm{pin}} g \cos \kappa\right) \tan \alpha+m_{p} g \sin \kappa+m_{\mathrm{pin}} g \sin \kappa \\
M_{s} & =-F_{g} d_{p}-m_{p} g \cos \kappa\left(d_{\mathrm{CM}}+d_{p}\right)+m_{p} g \\
& \cdot \sin \kappa\left(y_{P}-y_{\mathrm{CM}}\right)-\widetilde{F}_{I C}\left(d_{\mathrm{CM}}+d_{P}\right) \\
F_{s s} & =\left(j m_{\mathrm{cr}} \ddot{y}_{\mathrm{cr}}-j m_{\mathrm{cr}} g \cos \kappa\right) \tan \alpha+j m_{\mathrm{cr}} g \sin \kappa \\
& +j(1-j) m_{\mathrm{cr}} e_{c} \omega^{2} \sin \theta-\frac{\ddot{\alpha} I_{\mathrm{cr}}}{l_{\mathrm{cr}} \cos \alpha} .
\end{aligned}
$$

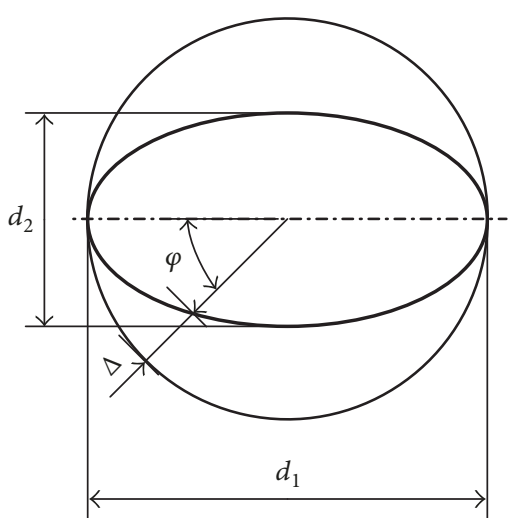

FIGURE 3: Horizontal profile of piston skirt.

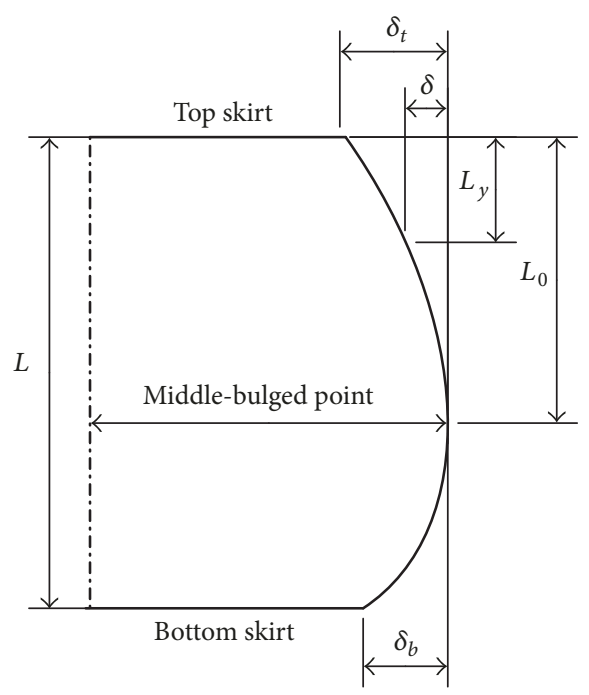

FIGURE 4: Longitudinal profile of piston skirt.

\section{Profile Design of Piston Skirt}

3.1. Horizontal Profile Design. The top surface of piston is acted upon by a larger gas pressure when the ICE operates; the piston expands outward along the pin direction because of the span between the right and left pin bosses. Therefore, the horizontal profile of piston skirt is designed as ellipse. In Figure $3, d_{1}, d_{2}$ are the diameters of the major and minor axis of ellipse, $\varphi$ is the circumferential angle, and $\Delta$ is the radial reduction of ellipse.

Because of the special structure and working condition of piston, the external expansion deformation of bottom skirt is more than top skirt. Therefore, the top ellipse profile of piston is designed to be slightly smaller than the bottom one.

3.2. Longitudinal Profile Design. In order to improve the lubrication condition of piston skirt, the longitudinal profile of piston skirt is generally designed as dolioform to reduce the friction force of the motion and strengthen the guidance effect. Meanwhile, it is beneficial to form the hydrodynamic oil film. The longitudinal profile is shown in Figure 4; $\delta$ is the radial reduction of longitudinal profile of the piston 
skirt, $\delta_{t}$ is the radial reduction of top skirt, $\delta_{b}$ is the radial reduction of bottom skirt, and $L_{0}$ is the distance from the middle-convex point to top skirt. The dolioform profiles of skirt are normally designed as parabola, ellipse, and circle curve.

\section{Mixed-Lubrication Model of Piston Skirt}

4.1. Hydrodynamic Lubrication Model. By considering the effect of lubricated surface roughness on flow of oil film, the oil film pressure between piston skirt and cylinder liner is solved using two-dimensional average Reynolds equation based on the theory proposed by Patir and Cheng $[33,34]$.

$$
\begin{aligned}
& \frac{\partial}{\partial x}\left(\phi_{x} h^{3} \frac{\partial p}{\partial x}\right)+\frac{\partial}{\partial y}\left(\phi_{y} h^{3} \frac{\partial p}{\partial y}\right) \\
& =6 \mu U\left(\frac{\partial h_{T}}{\partial x}+\sigma \frac{\partial \phi_{s}}{\partial x}\right)+12 \mu \frac{\partial h_{T}}{\partial t}
\end{aligned}
$$

where $h_{T}$ is the average value of actual oil film thickness, $p$ is the average hydrodynamic pressure, $h$ is the theoretical oil film thickness, $\mu$ is the dynamic viscosity of lubricant, $\sigma$ is the roughness of friction surface, $\phi_{x}$ and $\phi_{y}$ are the pressure flow factors, respectively, $\phi_{s}$ is the shear flow factor, and $U$ is the relative velocity between the piston skirt and cylinder liner.

The pressure flow factors $\phi_{x}, \phi_{y}[33]$ and shear flow factor $\phi_{s}$ [34] can be calculated as follows:

$$
\begin{aligned}
& \phi_{x}=\phi_{y}=1-0.9 e^{-0.56 H^{\prime}} \\
& \phi_{s} \\
& =\left\{\begin{array}{ll}
1.899 H^{\prime 0.98} \cdot \exp \left(-0.92 H^{\prime}+0.05 H^{\prime 2}\right) & H^{\prime \prime} \leq 5 \\
1.126 \cdot \exp \left(-0.25 H^{\prime}\right) & H^{\prime}>5
\end{array},\right.
\end{aligned}
$$

where $H^{\prime}=h / \sigma$ is the ratio of oil film thickness, $\sigma$ is the combined surface roughness, and $\Omega_{p}$ is the surface waviness of the piston.

Define touch factor $\phi_{c}=\partial \bar{h}_{T} / \partial h$ [35]; while $0 \leq H^{\prime}<3$, $\phi_{c}$ can be calculated from

$$
\begin{aligned}
\phi_{c} & =\exp \left(-0.6912+0.782 H^{\prime}-0.304 H^{\prime 2}\right. \\
& \left.+0.0401 H^{\prime 3}\right)
\end{aligned}
$$

while $H^{\prime} \geq 3, \phi_{c}=1$.

The Reynolds equation can be written as

$$
\begin{aligned}
& \frac{\partial}{\partial x}\left(\phi_{x} h^{3} \frac{\partial p}{\partial x}\right)+\frac{\partial}{\partial y}\left(\phi_{y} h^{3} \frac{\partial p}{\partial y}\right) \\
& \quad=6 \mu U \phi_{c} \frac{\partial h}{\partial x}+6 \mu U \sigma \frac{\partial \phi_{s}}{\partial x}+12 \mu \phi_{c} \frac{\partial h}{\partial t}
\end{aligned}
$$

$h$ can be calculated from

$$
\begin{aligned}
h(\varphi, y, t)= & c+e_{t}(t) \cos \varphi+\left[e_{b}(t)-e_{t}(t)\right] \frac{y}{L} \cos \varphi \\
& +f(\varphi, y) .
\end{aligned}
$$

By considering the elastic deformation of the piston, the oil film thickness can be rewritten as

$$
\begin{aligned}
h(\varphi, y, t)= & c+e_{t}(t) \cos \varphi+\left[e_{b}(t)-e_{t}(t)\right] \frac{y}{L} \cos \varphi \\
& +f(\varphi, y)+d(x, y),
\end{aligned}
$$

where $d(x, y)$ is the elastic deformation of the piston caused by the oil film pressure; $d(x, y)$ is obtained by the following formula [36]:

$$
d(x, y)=\frac{1}{\pi E^{\prime}} \int_{0}^{L} \int_{0}^{b} \frac{p(x, y) d x d y}{\sqrt{\left(x-x_{1}\right)^{2}-\left(y-y_{1}\right)^{2}}},
$$

where $E^{\prime}$ is the comprehensive elastic modulus of contact surface, which is related to elastic moduli $E_{1}, E_{2}$ and Poisson ratios of piston and cylinder liner $v_{1}, v_{2}$.

$$
E^{\prime}=2\left[\frac{\left(1-v_{1}^{2}\right)}{E_{1}}+\frac{\left(1-v_{2}^{2}\right)}{E_{2}}\right]
$$

By considering the symmetry of the structure of pistons skirt, the oil film force is calculated in a half of area $(\varphi=0 \sim$ $\pi)$. On major thrust side $(\varphi=0)$ and minor thrust side $(\varphi=$ $\pi$ ), the boundary conditions can be expressed as

$$
\left.\frac{\partial p}{\partial \varphi}\right|_{\varphi=0}=\left.\frac{\partial p}{\partial \varphi}\right|_{\varphi=\pi}=0
$$

On the top skirt $(y=0)$ and the bottom skirt $(y=L)$, the boundary conditions can be written as

$$
p(\varphi, 0)=p(\varphi, L)=0
$$

Because the squeeze effect of the oil film decreases gradually with the increase of the loading angle, it has smaller influence on the lubrication performance and the secondary motion. Taking certain value of loading angle, the oil film pressure approximates to zero outside of the loading angle area; the corresponding boundary condition is

$$
p=0 \quad\left(\varphi_{1} \leq \varphi \leq \varphi_{2}\right) .
$$

According to JFO boundary condition, the rupture boundary condition of oil film is

$$
\frac{\partial \bar{p}}{\partial n}=0 ;
$$


TABLE 1: The numbers of the node in $\varphi$ and $y$ directions.

\begin{tabular}{lcccc}
\hline$M(\varphi)$ & $N(y)$ & Oil film pressure at point 1 & Oil film pressure at point 2 & Oil film pressure at point 3 \\
\hline 36 & 20 & $554091 \mathrm{MPa}$ & $155160 \mathrm{MPa}$ & $103411 \mathrm{MPa}$ \\
50 & 30 & $559202 \mathrm{MPa}$ & $156861 \mathrm{MPa}$ & $103376 \mathrm{MPa}$ \\
80 & 60 & $561570 \mathrm{MPa}$ & $157100 \mathrm{MPa}$ & $103729 \mathrm{MPa}$ \\
\hline
\end{tabular}

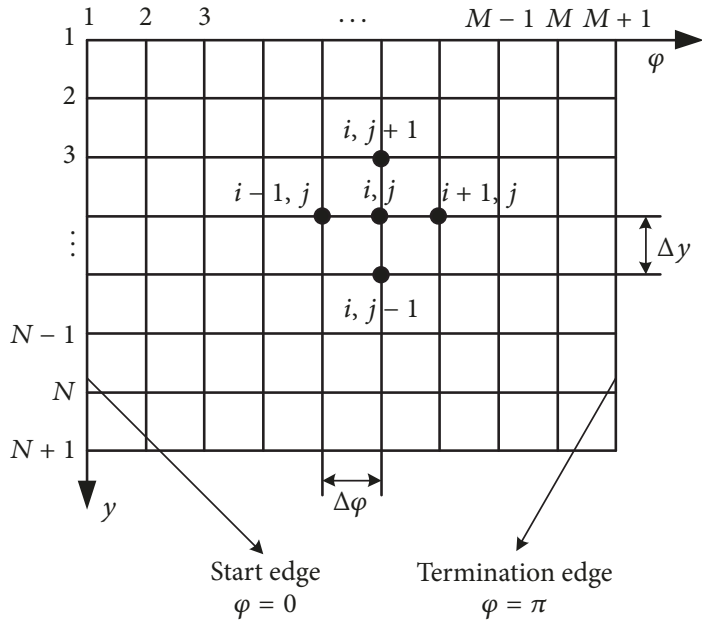

FIGURE 5: Grid of oil film region of the piston skirt.

the reformation boundary condition of oil film is

$$
\frac{h^{2}}{12 \mu} \frac{\partial p}{\partial n}=\frac{U_{n}}{2}\left(1-\frac{\rho}{\rho_{0}}\right),
$$

where $n$ is the flowing direction of the oil film.

In order to couple the full oil film zone and the cavitation zone and determine the rupture and reformation boundary of the oil film, the dimensionless independent variable $\phi$ and cavitation index $F$ are introduced:

$$
\begin{gathered}
F \phi=\bar{p} \quad(\phi \geq 0) \text { on full oil film region } \\
\frac{\rho}{\rho_{0}}-1=(1-F) \phi \quad \text { on rupture region of oil film, }
\end{gathered}
$$

where $\rho$ is the fluid density in the full film region and $\rho_{0}$ is the mix-density of the gas-fluid in the cavitation region.

The cavitation index $F$ is

$$
F=\left\{\begin{array}{ll}
1 & \phi \geq 0 \\
0 & \phi<0
\end{array} .\right.
$$

The Reynolds equation is converted into dimensionless equation and solved by the finite difference method.

As shown in Figure 5, the area of the oil film is divided into $M \times N$ elements. In the $\varphi$ direction, the number of the node is $M$ and the grid step is $\Delta \varphi$; in the $y$ direction, the number of the node is $N$ and the grid step is $\Delta y$.

The grid independence is verified for three sets of different numbers of the node in the $\varphi$ and $y$ directions. Table 1 shows the comparison of the oil film pressures for different numbers of the grid (the pressures are at three points. Point 1 for $\varphi=0^{\circ}, y=0.0414$; Point 2 for $\varphi=28.8^{\circ}, y=0.0207$; Point 3 for $\varphi=165^{\circ}, y=0.0621$; crankshaft angle is $90^{\circ}$ ). It can be seen that the changes of the oil film pressures are small with the increase of the grid number; the deviations among the oil film pressures are about $1 \%$ that can be neglected. The grid is independent of the calculations, but the calculation cost will increase when the grid with a bigger number is chosen. Therefore, the node numbers $M=36$ and $N=20$ are chosen as calculation grid number.

The tangential pressure of oil film on the skirt is calculated by (28).

$$
\tau_{h}=-\frac{\mu U}{h}\left(\Phi_{f}+\Phi_{f s}\right)+\Phi_{f p} \frac{h}{2} \frac{\partial p}{\partial y},
$$

where $\Phi_{f}, \Phi_{f s}$, and $\Phi_{f p}$ are shear stress factors related to lubrication surface roughness [37].

4.2. Solid-to-Solid Contact Model. Because the instantaneous gas pressure of piston is variable, the lubricant film thickness between the piston skirt and cylinder liner may get thinner during strenuous movement. Therefore, the solid-solid contact may be caused by the collision of the surface asperity by considering the surface roughness. In this situation, the total lateral thrust force consists of the lateral thrust force of oil film and lateral thrust force of solid-solid contact and the total friction force consists of the oil film shear stress and asperity shear stress.

The ratio of oil film thickness $H^{\prime}$ is normally used to evaluate the lubrication condition; when $H^{\prime} \geq 4$, the piston skirt-cylinder liner system is under hydrodynamic lubrication condition; when $H^{\prime}<4$, the piston skirtcylinder liner system is under mixed-lubrication condition, and asperity contact [38] is inescapable.

Based on the rough surface contact theory presented by Greenwood and Tripp [39], the solid-solid contact pressure $p_{c}$ of the piston skirt and cylinder liner is calculated by

$$
p_{c}=\frac{16 \sqrt{2}}{15} \pi(\eta \beta \sigma)^{2} E^{\prime} \sqrt{\frac{\sigma}{\beta}} F_{5 / 2}\left(H^{\prime}\right),
$$

where $\eta$ is the asperity density of the rough surface, $\beta$ is the radius of the asperity curvature, and $\eta \beta \sigma=0.03 \sim 0.05, \sigma / \beta=$ $10^{-4} \sim 10^{-2}$.

$$
\alpha_{c}=\pi^{2}(\eta \beta \sigma)^{2} F_{2}\left(H^{\prime}\right) \text {, }
$$

where $\alpha_{c}$ is the asperity contact area. 
The shear force $\tau_{c}$ of solid-solid contact of piston skirt and cylinder liner is

$$
\tau_{c}=\mu_{f} \cdot p_{c}
$$

where $\mu_{f}$ is the frictional coefficient of solid-solid contact.

4.3. Calculation of Force and Moment. The lateral thrust force $F_{h}$ caused by hydrodynamic lubrication is

$$
F_{h}=R \int_{0}^{L} \int_{0}^{2 \pi} p \cos \varphi d \varphi d y
$$

The lateral thrust moment $M_{h}$ caused by hydrodynamic lubrication is

$$
M_{h}=R \int_{0}^{L} \int_{0}^{2 \pi} p \cos \varphi\left(y_{P}-y\right) d \varphi d y .
$$

The friction force $F_{f h}$ caused by hydrodynamic lubrication is

$$
F_{f h}=-\operatorname{sign}(U) R \int_{0}^{L} \int_{0}^{2 \pi} \tau_{h} d \varphi d y,
$$

where $\operatorname{sign}(U)$ is sign function.

The friction torque $M_{f h}$ caused by hydrodynamic lubrication is

$$
M_{f h}=\operatorname{sign}(U) R \int_{0}^{L} \int_{0}^{2 \pi} \tau_{h} R \cos \varphi d \varphi d y .
$$

The lateral thrust $F_{c}$ caused by solid-solid contact is

$$
F_{c}=R \int_{0}^{L} \int_{0}^{2 \pi} p_{c} \cos \varphi d \varphi d y .
$$

The lateral thrust moment $M_{c}$ caused by solid-solid contact is

$$
M_{c}=R \int_{0}^{L} \int_{0}^{2 \pi} p_{c} \cos \varphi\left(y_{P}-y\right) d \varphi d y .
$$

The friction force $F_{f c}$ caused by solid-solid contact is

$$
F_{f c}=-\operatorname{sign}(U) R \int_{0}^{L} \int_{0}^{2 \pi} \tau_{c} d \varphi d y
$$

The friction moment $M_{f c}$ caused by solid-solid contact is

$$
M_{f c}=\operatorname{sign}(U) R \int_{0}^{L} \int_{0}^{2 \pi} \tau_{c} R \cos \varphi d \varphi d y .
$$

The total lateral thrust force $F_{t}$ of piston skirt is

$$
F_{t}=F_{h}+F_{c}
$$

The total friction force $F_{f}$ of piston skirt is

$$
F_{f}=F_{f h}+F_{f c}
$$

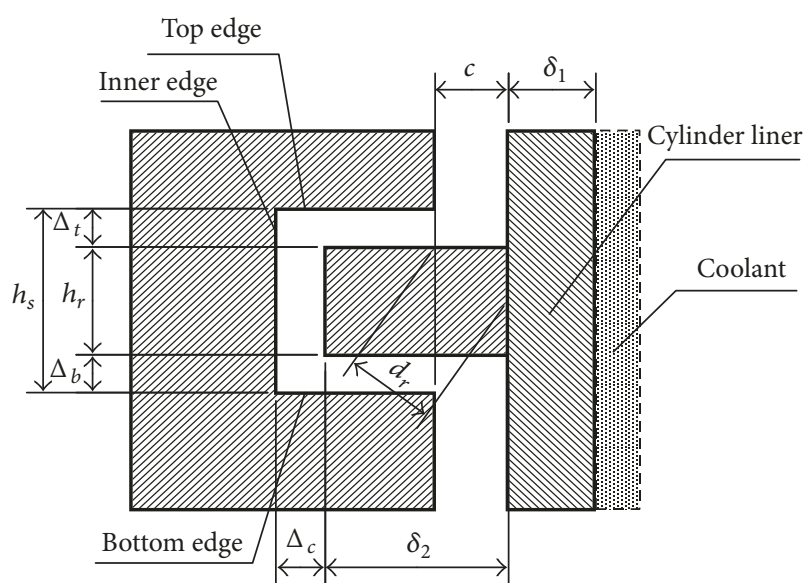

FIGURE 6: Structure of piston ring groove area.

The total lateral thrust moment $M_{t}$ of piston skirt is

$$
M_{t}=M_{h}+M_{c}
$$

The total friction torque $M_{f}$ of piston skirt is

$$
M_{f}=M_{f h}+M_{f c}
$$

\section{Thermal Analysis Model of Piston}

The heat of the piston side is mainly transferred to the oil film and gas film in the cylinder clearance through the piston junk, piston ring, and piston skirt surface. Then the heat is transferred to coolant outside of cylinder liner through cylinder liner. The coolant is considered as heat conduction terminal. Figure 6 shows the structure of the piston ring groove.

The heat transfer of the piston and cylinder liner is simplified to steady state heat conduction in multilayer flat wall; the heat transfer of cylinder liner and coolant is simplified to convective heat conduction state.

$$
\Phi=\frac{t_{w 1}-t_{w 4}}{\delta_{1} / \lambda_{1} A+\delta_{2} / \lambda_{2} A+\delta_{3} / \lambda_{3} A+\delta_{4} / \lambda_{4} A},
$$

where $\Phi$ is the heat flow of the heat conduction, $t_{w 1}$ and $t_{w 4}$ are the starting and terminal temperature, respectively, $\delta_{1}$ is the thickness of gas or lubricant, $\delta_{2}$ is the thickness of piston ring, $\delta_{3}$ is the thickness of cylinder wall, $\lambda_{1}$ is the heat conduction coefficient of gas $\lambda_{g}$ or heat conduction coefficient of lubricant $\lambda_{o}, \lambda_{g}=0.023 \mathrm{~W} /\left(\mathrm{m}^{2} \cdot \mathrm{K}\right), \lambda_{o}=$ $0.4 \mathrm{~W} /\left(\mathrm{m}^{2} \cdot \mathrm{K}\right), \lambda_{2}$ is the heat conduction coefficient of piston ring, $\lambda_{2}=0.2 \mathrm{~W} /\left(\mathrm{m}^{2} \cdot \mathrm{K}\right), \lambda_{3}$ is the heat conduction coefficient of cylinder liner, $\lambda_{4}$ is the convective heat conduction coefficient of cylinder liner and coolant, and $A$ is the heat conduction area; the heat conduction coefficient $a$ of different positions of the piston side is deduced from deformation formula of (44).

$$
a=\frac{1}{\delta_{1} / \lambda_{1}+\delta_{2} / \lambda_{2}+\delta_{3} / \lambda_{3}+1 / \lambda_{4}} .
$$




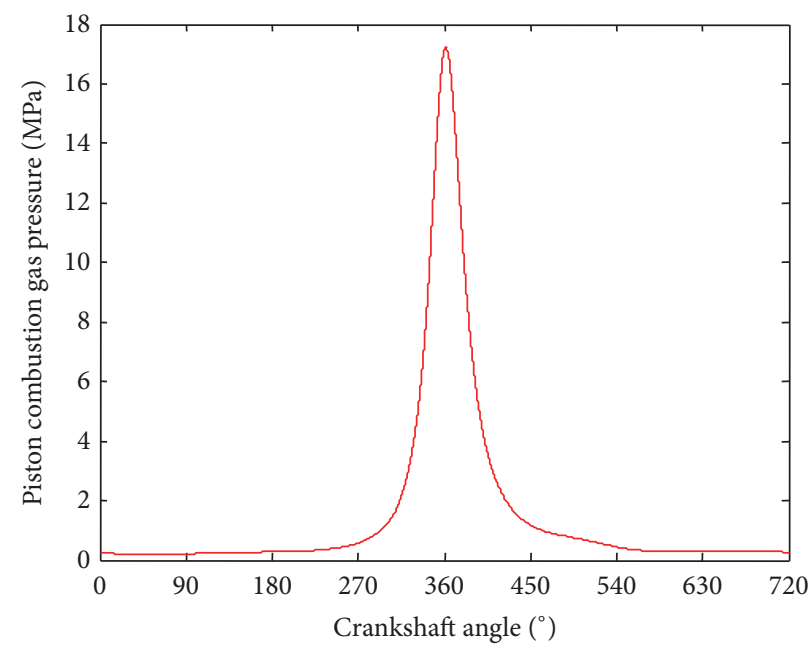

FIgURE 7: Gas pressure inside of cylinder.

The piston side consists of the piston junk, piston ring groove, piston ring land, piston pin area, and piston skirt. Because the structures are different in different areas, the calculation of heat conduction coefficients is different.

The heat conduction of the coolant and cylinder liner is simplified to convection heat transfer from tube banks in crossflow. According to strong turbulence formula and Nusselt number definition, the convective heat conduction coefficients of cylinder liner and coolant are obtained

$$
\lambda_{4}=\frac{0.023 \operatorname{Re}_{f}^{0.8} \operatorname{Pr}_{f}^{m} k}{L},
$$

where $\lambda_{4}$ are the convective heat conduction coefficients of cylinder liner and coolant, $\operatorname{Re}_{f}$ is within $10^{4} \sim 1.2 \times 10^{5}, \operatorname{Re}_{f}=$ $11000, \operatorname{Pr}_{f}$ is within $0.7 \sim 160, \operatorname{Pr}_{f}=100$, when the fluid is heated by pipe, $m=0.4, k$ is the heat conduction coefficient of static fluid, $k=0.0036 \mathrm{~W} /(\mathrm{m} \cdot \mathrm{K})$, and $L$ is the geometric characteristic length, $L=0.005 \mathrm{~m}$.

When the inner of cylinder liner contacts with the oilgas mixture, the convective heat conduction coefficient is calculated by the following equation:

$$
a_{c}=\frac{1}{\delta_{c} / \lambda_{c}},
$$

where $a_{c}$ is the convective heat conduction coefficient of the inner of the cylinder liner, $\delta_{c}$ is the thickness of the oil-gas mixture of the inner of the cylinder liner, and $\lambda_{c}$ is the heat conduction coefficient of oil-gas mixture.

\section{Model Solutions}

Equation (11) is solved by the Runge-Kutta method. Taking the four-stroke ICE as an example, the piston motion is periodic motion. The simulation of the secondary motion is conducted in an engine cycle (i.e., the crankshaft angle is from $0^{\circ}$ to $\left.720^{\circ}\right)$, the time step is $\Delta t=2 \times 10^{-6} \mathrm{~s}$, the initial values $e_{t}, e_{b}, \dot{e}_{t}, \dot{e}_{b}, \ddot{e}_{t}$, and $\ddot{e}_{b}$ at the moment $t_{i}$ are provided, and the oil film pressure and solid-solid contact pressure of the hydrodynamic lubrication are calculated by coupling the motion parameters of the crankshaft connecting rod system. The shear stress of oil film and solid-solid contact shear stress are solved by (28) and (31), and the force and moment are calculated using integral formula. The values $e_{t}, e_{b}, \dot{e}_{t}, \dot{e}_{b}$, $\ddot{e}_{t}$, and $\ddot{e}_{b}$ at the moment $t_{i+1}$ are calculated by the RungeKutta method. Repeat the above procedure until meeting convergence criteria.

$$
\begin{aligned}
& e_{t}-e_{t}\left(t+\frac{4 \pi}{\omega}\right)<10^{-5} \\
& e_{b}-e_{b}\left(t+\frac{4 \pi}{\omega}\right)<10^{-5} \\
& \dot{e}_{t}-\dot{e}_{t}\left(t+\frac{4 \pi}{\omega}\right)<10^{-5} \\
& \dot{e}_{b}-\dot{e}_{b}\left(t+\frac{4 \pi}{\omega}\right)<10^{-5},
\end{aligned}
$$

where $\omega$ is the rotational angular velocity of the crankshaft. The convergence can be obtained after calculating 2-3 cycles.

\section{Numerical Examples}

The simulation of the piston secondary motion is carried out in a certain-type four-stroke four-cylinder turbocharged diesel engine. The parameters used in the simulation are listed in Tables 2 and 3 . Table 2 shows the structure parameters of engine. Table 3 shows the material characteristic parameters of piston and cylinder liner. The variation curve of the gas pressure for different crankshaft angles is shown in Figure 7, when the rotation speed is $1680 \mathrm{rpm}$.

Figure 8 shows the comparison of the secondary motions of the piston with and without considering elastic deformation. When the elastic deformation of the piston is considered, the maximum secondary displacement and velocity increase, respectively, about $0.15 \%$ and $0.37 \%$, the maximum 
TABLE 2: Structure parameters of engine.

\begin{tabular}{|c|c|c|}
\hline Symbol & Definition & Value \\
\hline$R$ & Piston radius & $55 \mathrm{~mm}$ \\
\hline$L$ & Piston skirt length & $82.8 \mathrm{~mm}$ \\
\hline$r$ & Crankshaft radius & $72 \mathrm{~mm}$ \\
\hline$l_{A B}$ & Connecting rod length & $223 \mathrm{~mm}$ \\
\hline$l_{A C}$ & Connecting rod center-of-mass location & $72 \mathrm{~mm}$ \\
\hline$y_{\mathrm{CM}}$ & Piston center-of-mass location & $10.8 \mathrm{~mm}$ \\
\hline$y_{P}$ & Piston pin axial location & $37.3 \mathrm{~mm}$ \\
\hline$m_{P}$ & Piston mass & $1.39 \mathrm{~kg}$ \\
\hline$I_{p}$ & Piston inertia moment & $0.003 \mathrm{~kg} \cdot \mathrm{m}^{2}$ \\
\hline$m_{\mathrm{cr}}$ & Connecting rod mass & $1.7 \mathrm{~kg}$ \\
\hline$I_{b}$ & Connecting rod inertia moment & $0.017 \mathrm{~kg} \cdot \mathrm{m}^{2}$ \\
\hline$m_{c}$ & Crankshaft mass & $23.5 \mathrm{~kg}$ \\
\hline$I_{c}$ & Crankshaft moment of inertia & $2 \mathrm{~kg} \cdot \mathrm{m}^{2}$ \\
\hline$\Omega$ & Crankshaft rotation speed & $1680 \mathrm{rpm}$ \\
\hline$c$ & Theoretical piston skirt clearance & $50 \mu \mathrm{m}$ \\
\hline$\sigma_{s}$ & Piston surface roughness & $0.20 \mu \mathrm{m}$ \\
\hline$\Omega_{p}$ & External waviness root-mean-square value of piston & $20 \mu \mathrm{m}$ \\
\hline$\sigma_{b}$ & Inner hole surface roughness & $0.50 \mu \mathrm{m}$ \\
\hline$\sigma$ & Combined roughness & $0.54 \mu \mathrm{m}$ \\
\hline$E$ & Modulus of elasticity (Al) & $79 \mathrm{GPa}$ \\
\hline$\mu$ & Viscosity $\left(100^{\circ}\right.$, SAE $\left.10 \mathrm{~W} 40\right)$ & $0.0056 \mathrm{~Pa} \cdot \mathrm{s}$ \\
\hline$\mu_{f}$ & Solid-solid friction coefficient & 0.1 \\
\hline$d_{c}$ & Offset of crankshaft & $0 \mathrm{~mm}$ \\
\hline$d_{p}$ & Offset of pin & $0 \mathrm{~mm}$ \\
\hline$d_{\mathrm{CM}}$ & Offset of center of mass & $0 \mathrm{~mm}$ \\
\hline$\kappa$ & Cylinder axial tilting angle & $0^{\circ}$ \\
\hline
\end{tabular}

TABLE 3: Characteristic parameters of piston material.

\begin{tabular}{lcc}
\hline Physical quantity & Piston (eutectic Al Si alloy) & Cylinder liner (boron cast iron) \\
\hline Thermal conductivity $\left(\lambda / \mathrm{W} \cdot \mathrm{m}^{-1} \cdot \mathrm{K}^{-1}\right)$ & 145 & 42 \\
Density $\left(\rho / \mathrm{kg} / \mathrm{m}^{-3}\right)$ & 2700 & 7370 \\
Specific heat capacity $\left(c_{p} / \mathrm{J} \cdot \mathrm{kg}^{-1} \cdot \mathrm{K}^{-1}\right)$ & 880 & 470 \\
Elasticity modulus $(E / \mathrm{GPa})$ & 71 & 159 \\
Poisson ratio $(\nu)$ & 0.34 & 0.3 \\
Coefficient of linear expansion $\left(\alpha / \mathrm{K}^{-1}\right)$ & $2 \times 10^{-6}$ & $12 \times 10^{-6}$ \\
\hline
\end{tabular}

of the minimum oil film thickness increases about $0.20 \%$, and the friction force and friction power loss increase, respectively, about $0.015 \%$ and $0.016 \%$. From Figure 8 , it can be seen that the effect of elastic deformations is small within the selected data set, and therefore the piston was assumed to be rigid. So the elastic deformation of the piston is not considered as the influence factor in the current work.
7.1. Effect of the Boundary Condition on Secondary Motion. Figure 9 shows the comparison of secondary motions of the piston under the Reynolds and JFO boundary conditions. By considering the rupture and reformation boundaries of oil film, the secondary displacement, velocity, and the tilting angle under JFO boundary condition decrease obviously. Compared with the Reynolds boundary condition, because of the change of the oil film pressure, the maximum of the 


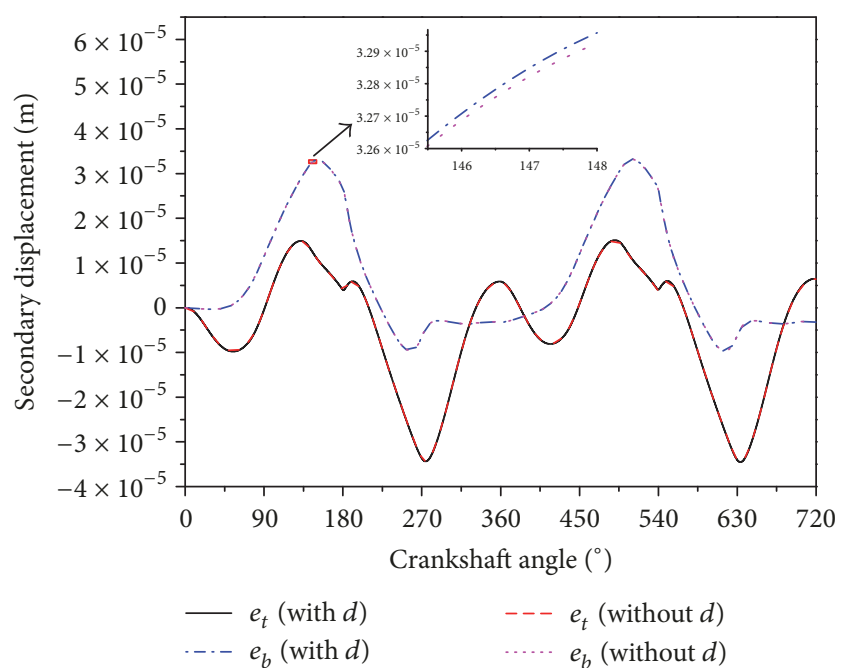

(a) Secondary displacement

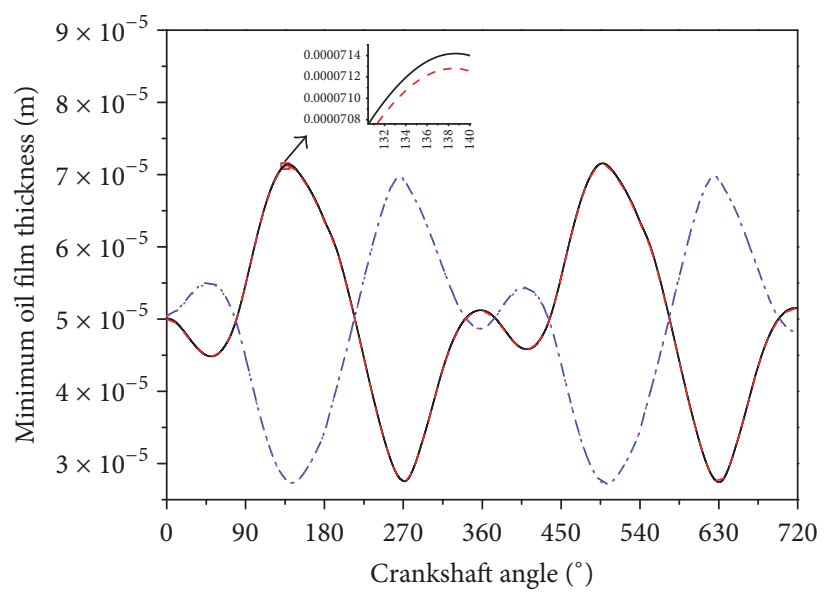

— Major oil film thickness (with $d$ )

...- Minor oil film thickness (with $d$ )

- - - Major oil film thickness (without $d$ )

..... Minor oil film thickness (without $d$ )

(c) Minimum oil film thickness

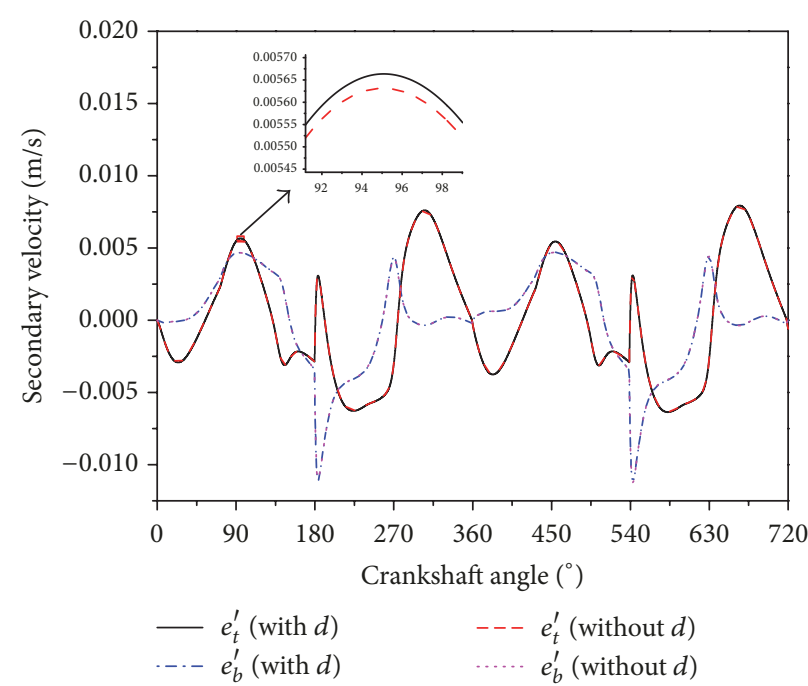

(b) Secondary velocity

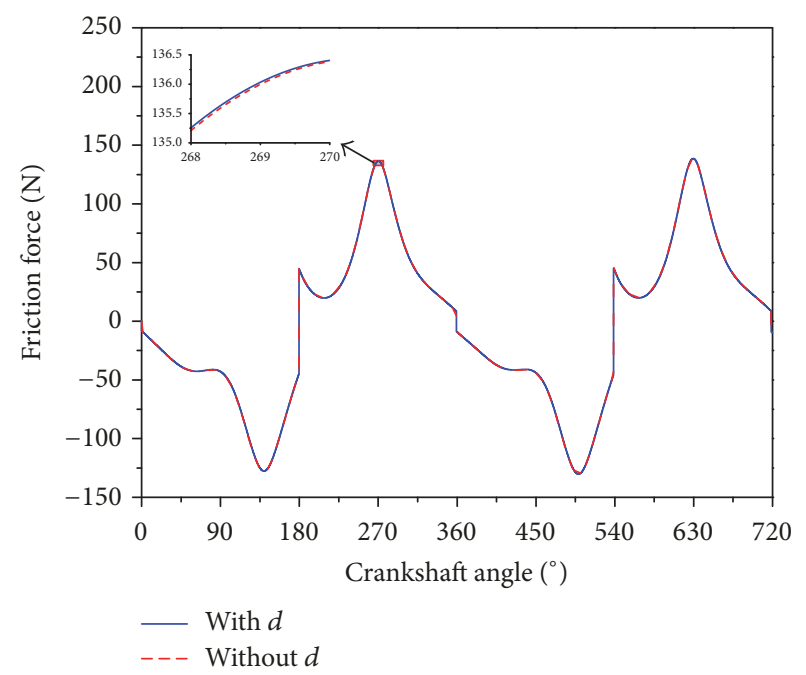

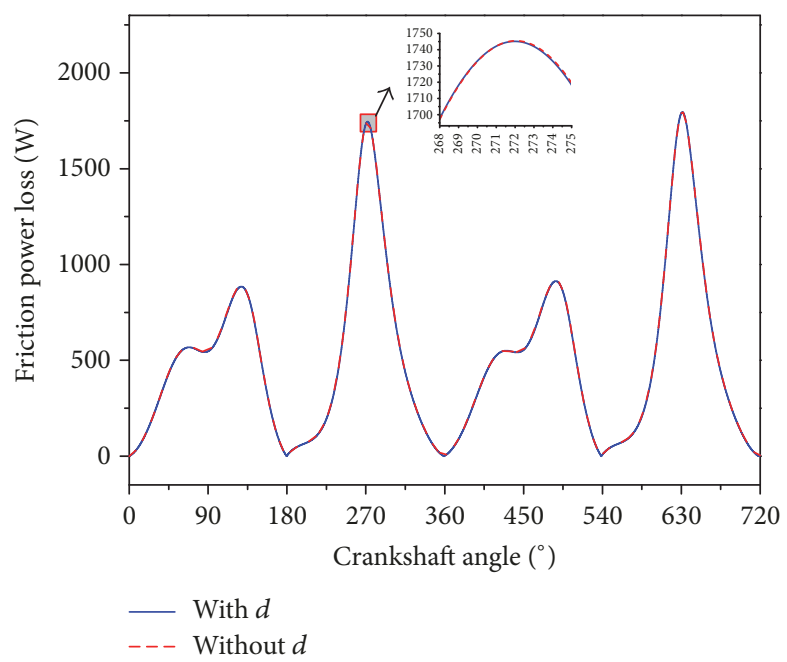

(e) Friction power loss

FIGURE 8: Comparison of secondary motions of the piston with and without elastic deformation. 


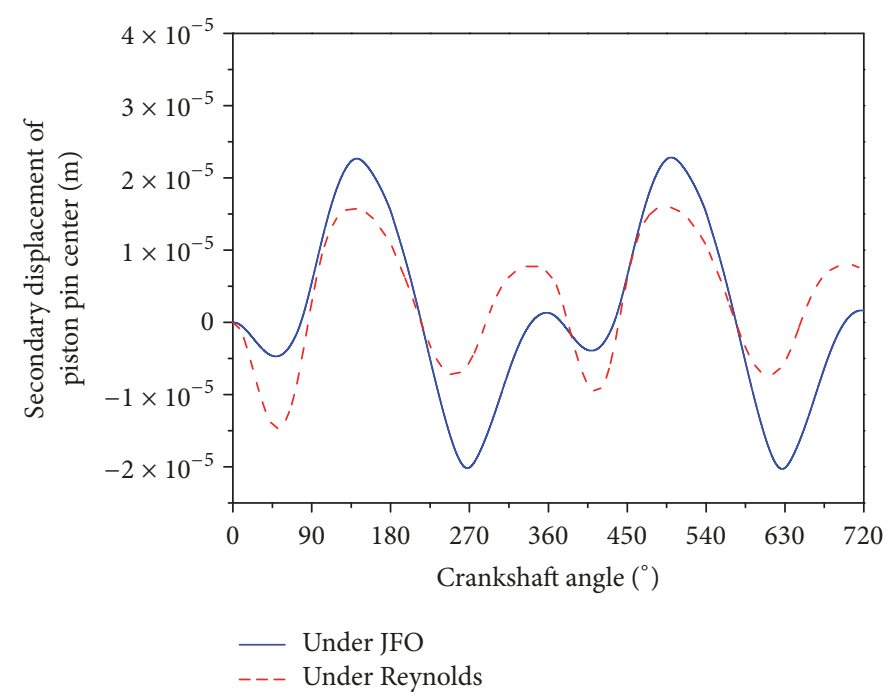

(a) Displacement of the center of the piston pin

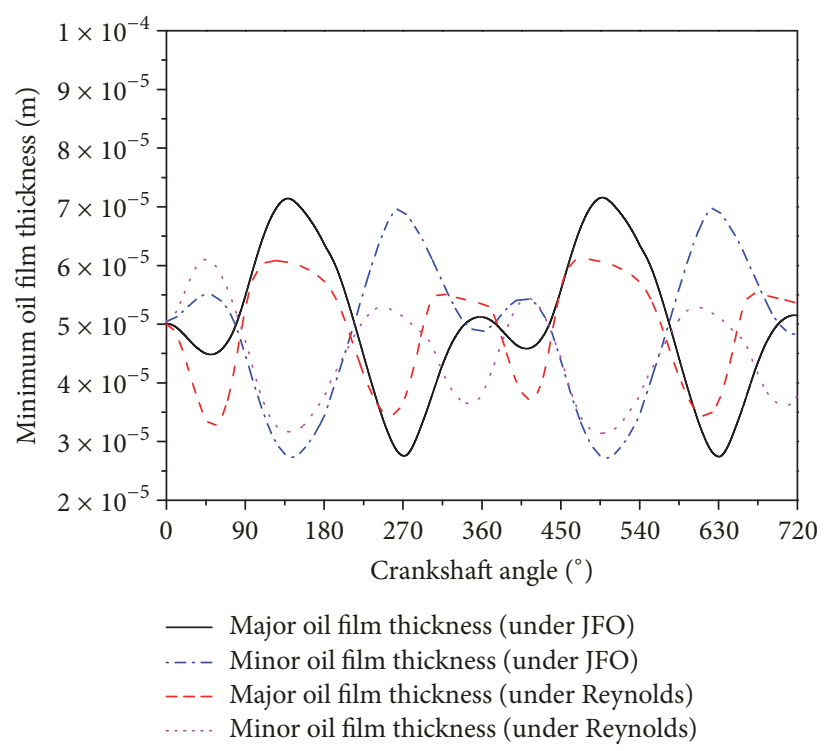

(c) Minimum oil film thickness

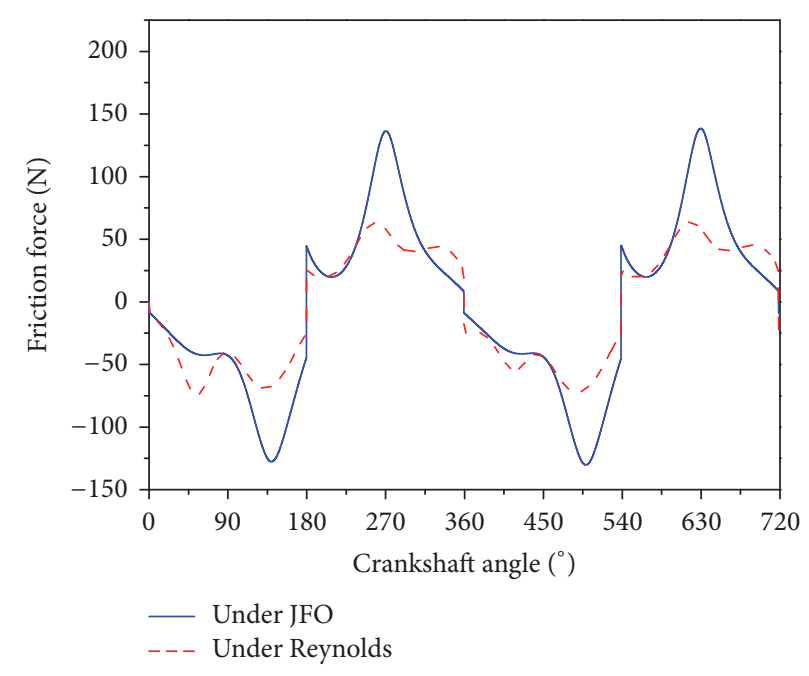

(b) Friction force

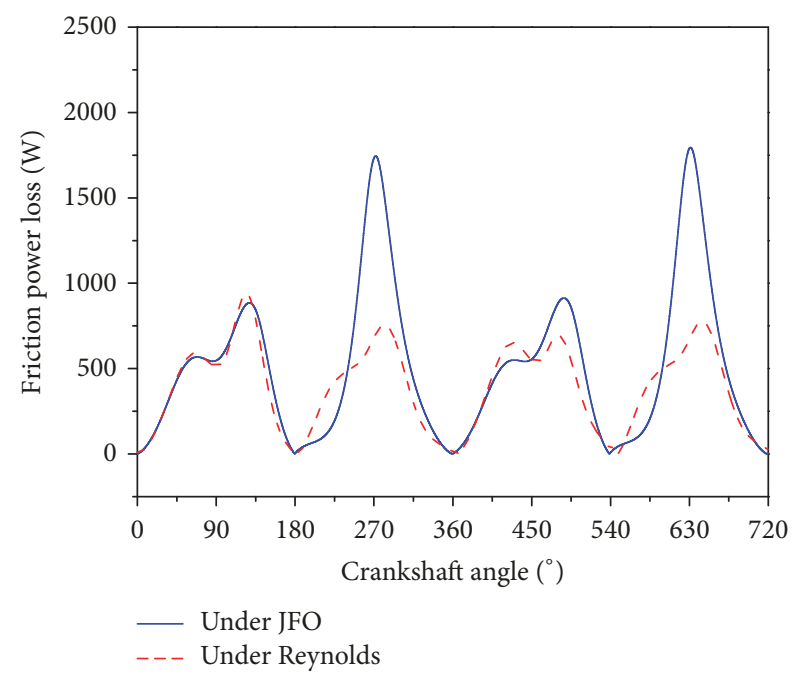

(d) Friction power loss

FIGURE 9: Comparison of secondary motions of the piston under the Reynolds and JFO boundary conditions.

minimum oil film thickness on major thrust side increases at $135^{\circ}$ and $495^{\circ}$ and decreases at $270^{\circ}$ and $630^{\circ}$; the corresponding friction force and friction power loss increase to the peak at $270^{\circ}$ and $630^{\circ}$. The maximum friction force and friction power loss under JFO boundary condition increase, respectively, about $48.4 \%$ and $44.7 \%$. The results show that the reformation of oil film has effect on piston secondary motion, so it is necessary to investigate the lubrication performance of the piston using JFO boundary condition.

7.2. Effect of Connecting Rod Inertia on Secondary Motion. Figure 10 shows the curve of secondary motion of the piston by considering the inertia of the connecting rod. The connecting rod inertia leads to the obvious change of the oil film pressure during the compression stroke and exhaust stroke, and the change of the pressure has an important influence on the secondary motion. In a cycle, the maximum secondary displacement and velocity and the maximums of the minimum oil film thicknesses on major and minor thrust sides increase slightly, the maximum thrust and friction forces increase, respectively, about $15.5 \%$ and $7.9 \%$, the piston tilting angle has obvious increase at $360^{\circ}$ and $720^{\circ}$, and the maximum friction power loss increases $6 \%$. By considering the effect of the connecting rod inertia, the secondary motion is closer to the actual working condition, so the inertia of connecting rod is taken into consideration in the following numerical examples. 

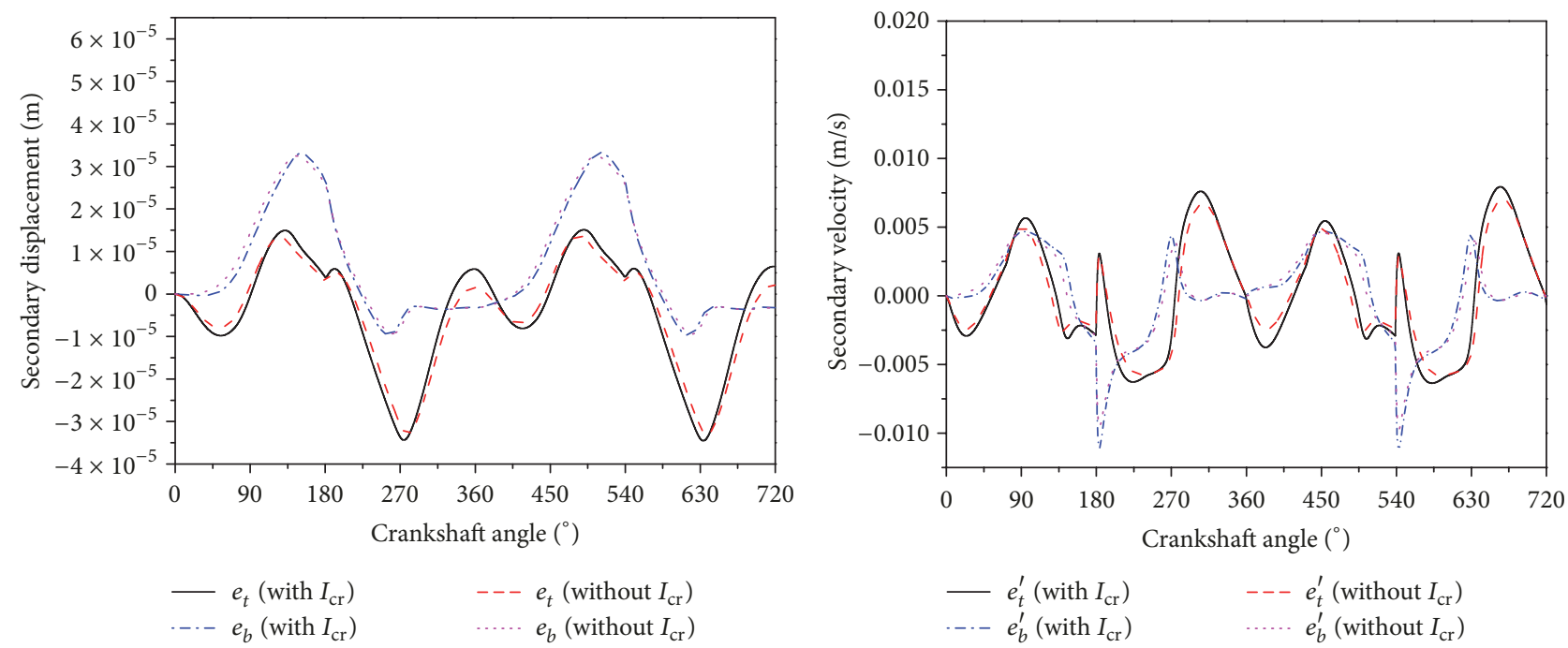

(a) Secondary displacement

(b) Secondary velocity
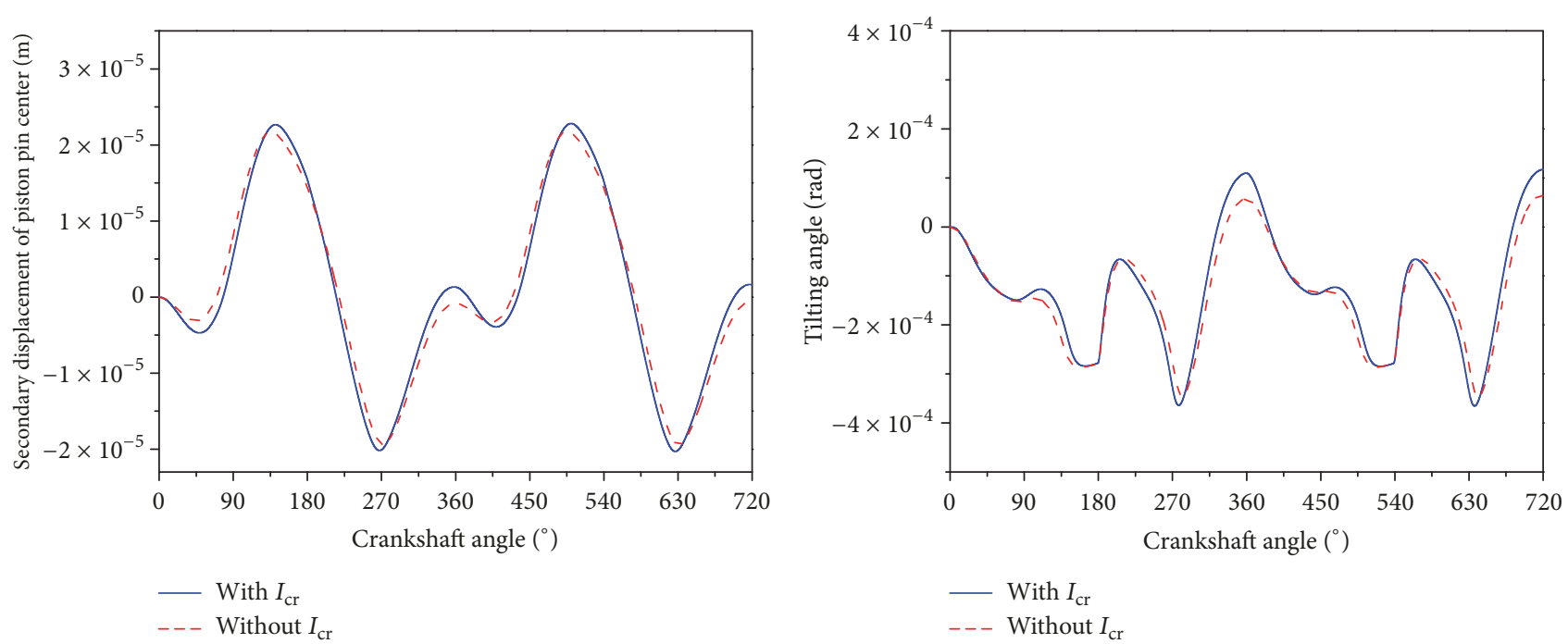

(c) Displacement of the center of the piston pin

(d) Piston tilting angle
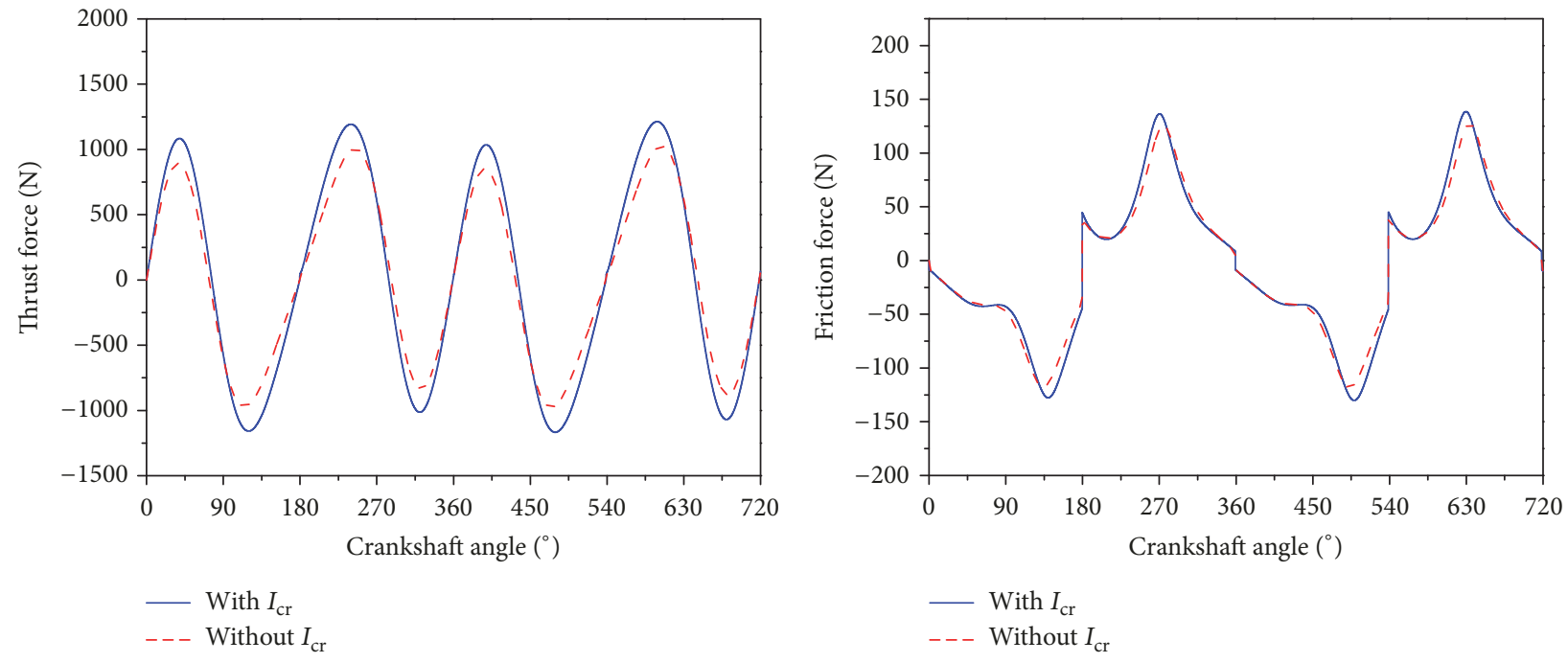

(e) Lateral thrust force

(f) Friction force

Figure 10: Continued. 


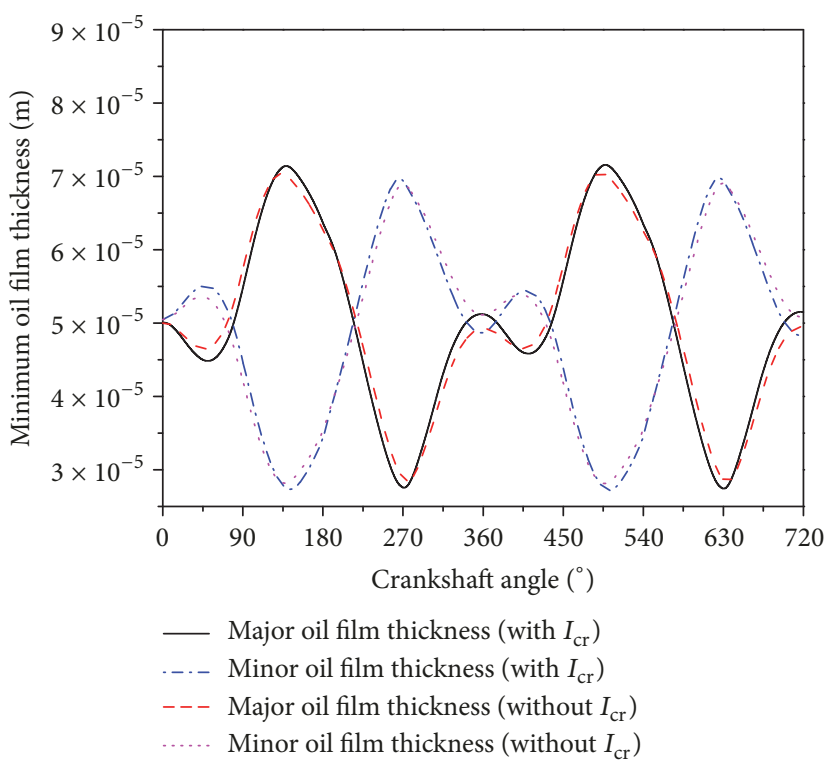

(g) Minimum oil film thickness

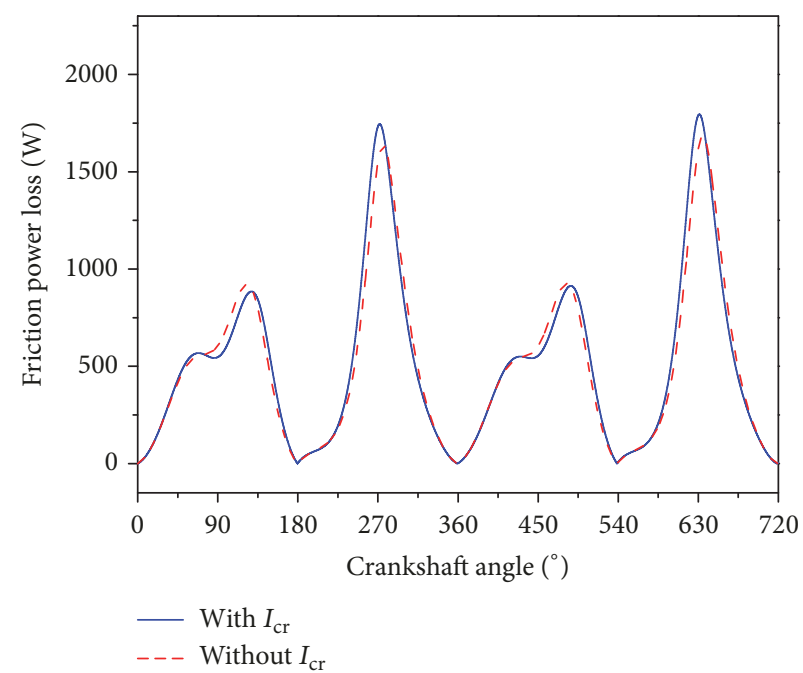

(h) Friction power loss

FIGURE 10: Effect of connecting rod inertia on secondary motion.

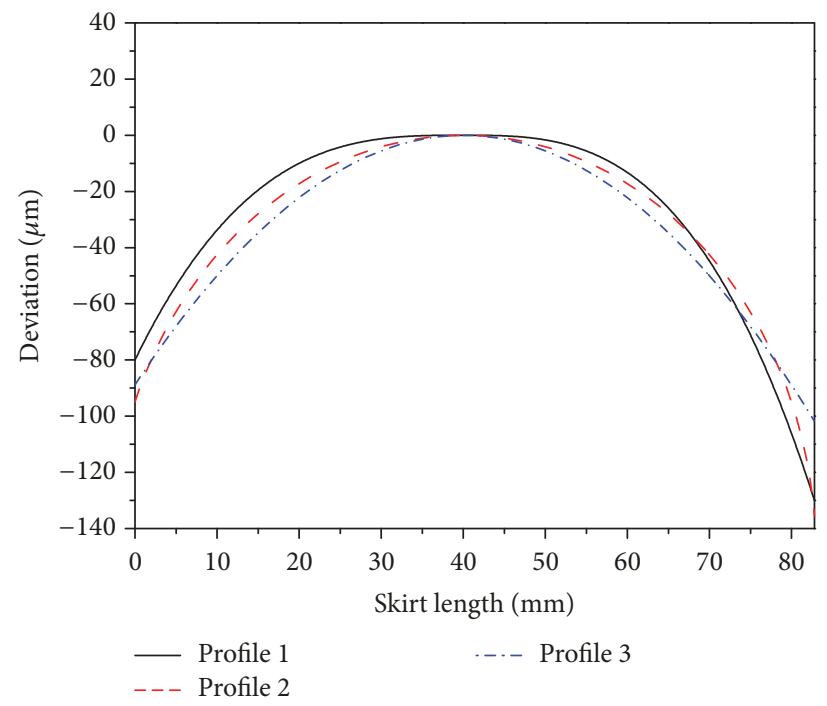

FIGURE 11: Profiles of different longitudinal profile skirts.

7.3. Effect of Longitudinal Profile on Lubrication Performance. Figure 11 shows the profiles of three different longitudinal profile skirts. Profile 1 is the profile of parabola (the deviations of top and bottom skirts are, resp., $80 \mu \mathrm{m}$ and $130 \mu \mathrm{m}$ ), profile 2 is the profile of ellipse (the deviations of top and bottom skirts are, resp., $94.95 \mu \mathrm{m}$ and $135.55 \mu \mathrm{m})$, and profile 3 is the circular curve (the deviations of top and bottom skirts are, resp., $88.89 \mu \mathrm{m}$ and $101.77 \mu \mathrm{m})$. Figure 12 shows the effects of different profiles on lubrication performance of the piston-cylinder liner system. The secondary displacements and velocities of top and bottom skirts and the maximum of the minimum oil film thickness of profile 1 decrease obviously contrasting with profiles 2 and 3 , and the maximum tilting angle of profile 1 decreases. Due to the decrease of the minimum oil film thickness, the friction force and friction power loss increase slightly. By considering the secondary motion of three profiles comprehensively, profile 1 is chosen as longitudinal profile.

7.4. Effect of Radial Reduction on Lubrication Performance. Figure 13 shows the skirt profiles of different radial reductions on the top and bottom skirts, the deviations of top and bottom skirts of profile 1 are, respectively, $80 \mu \mathrm{m}$ and $130 \mu \mathrm{m}$, the deviations of profile 4 are both $100 \mu \mathrm{m}$, and the deviations of 


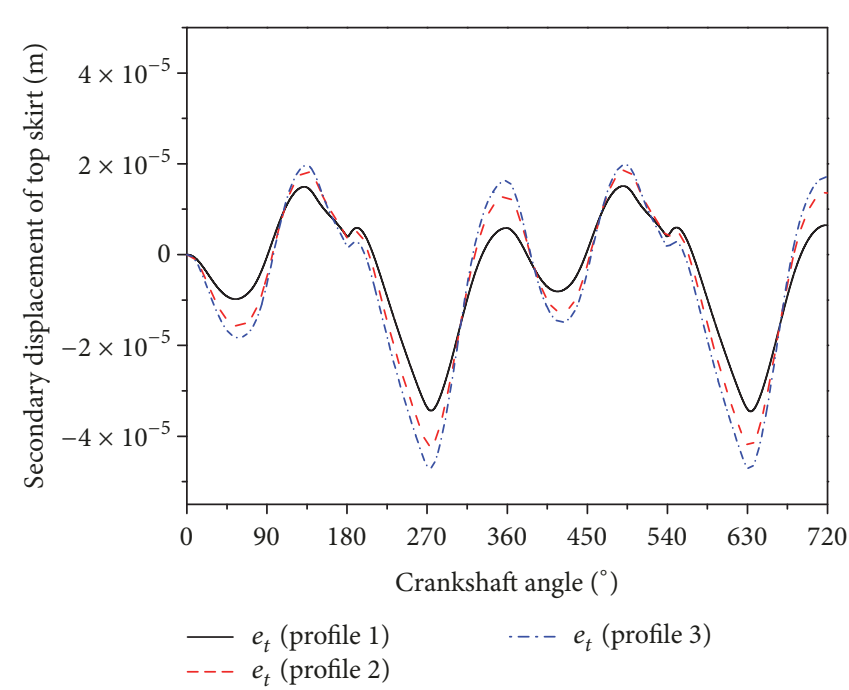

(a) Secondary displacement of top skirt

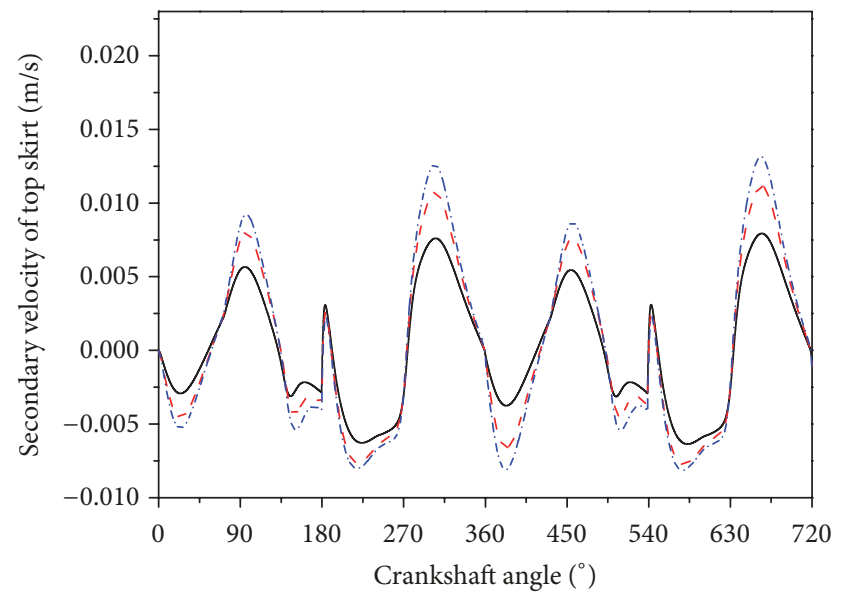

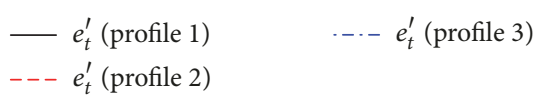

(c) Secondary velocity of top skirt

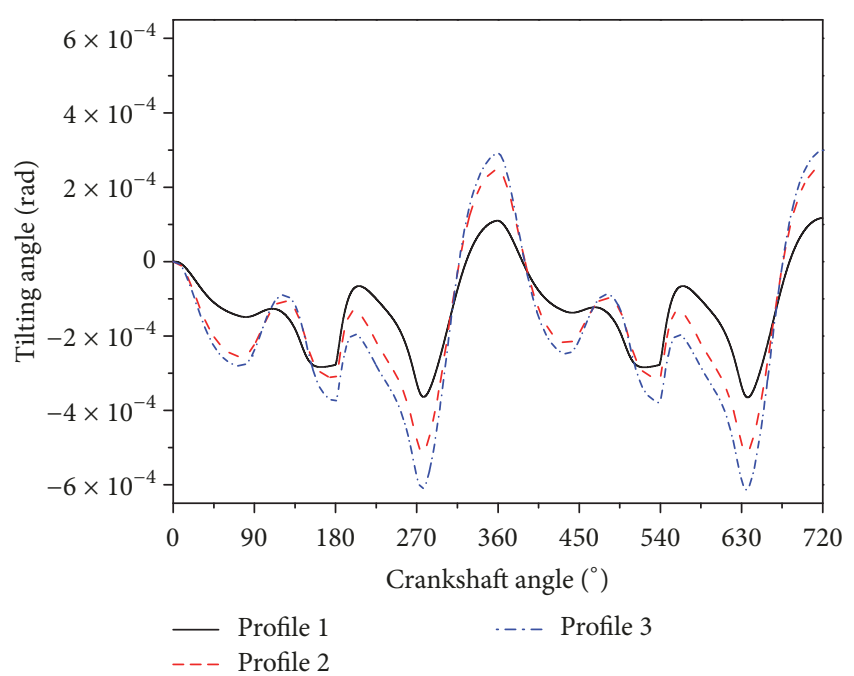

(e) Piston tilting angle

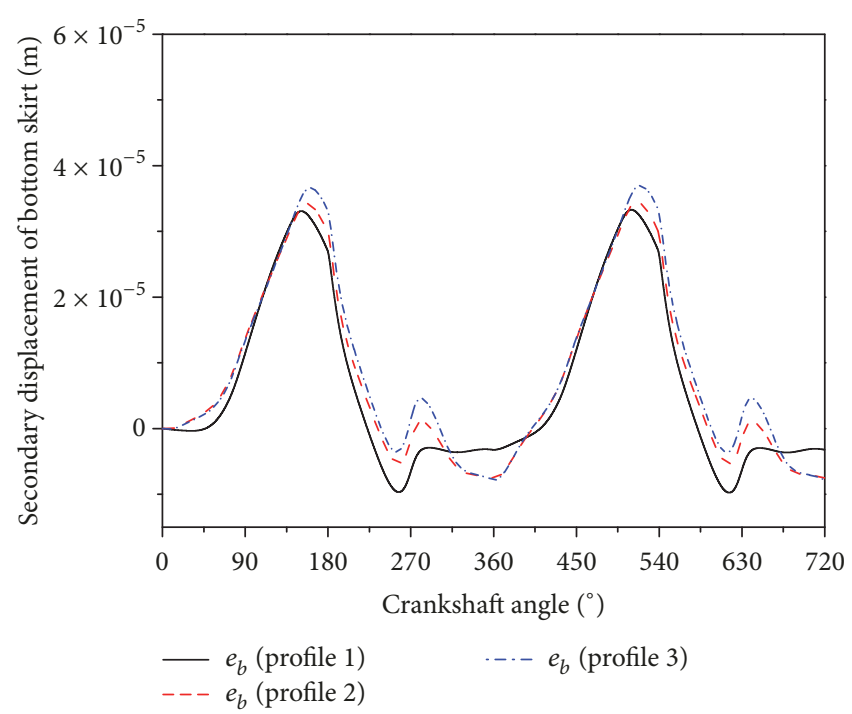

(b) Secondary displacement of bottom skirt

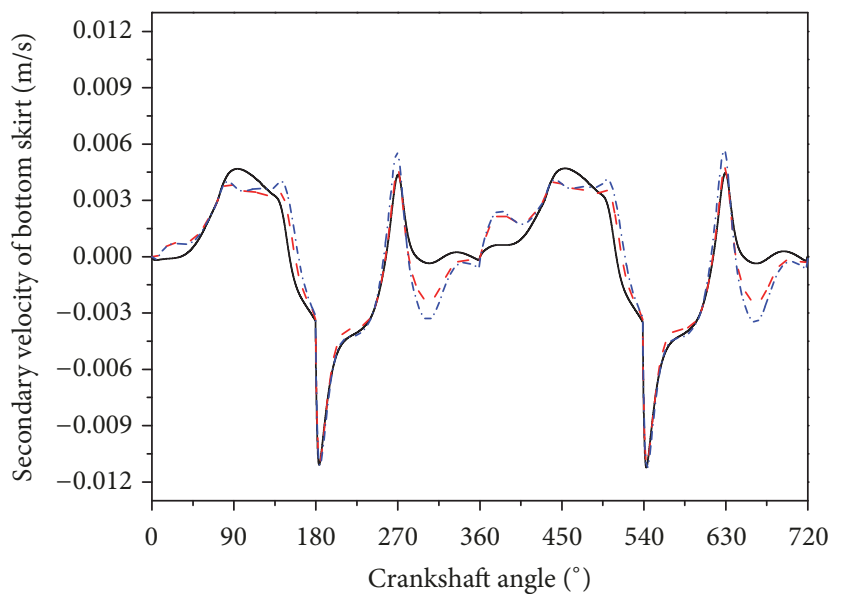

- Profile 1

-..- Profile 3

- - Profile 2

(d) Secondary velocity of bottom skirt

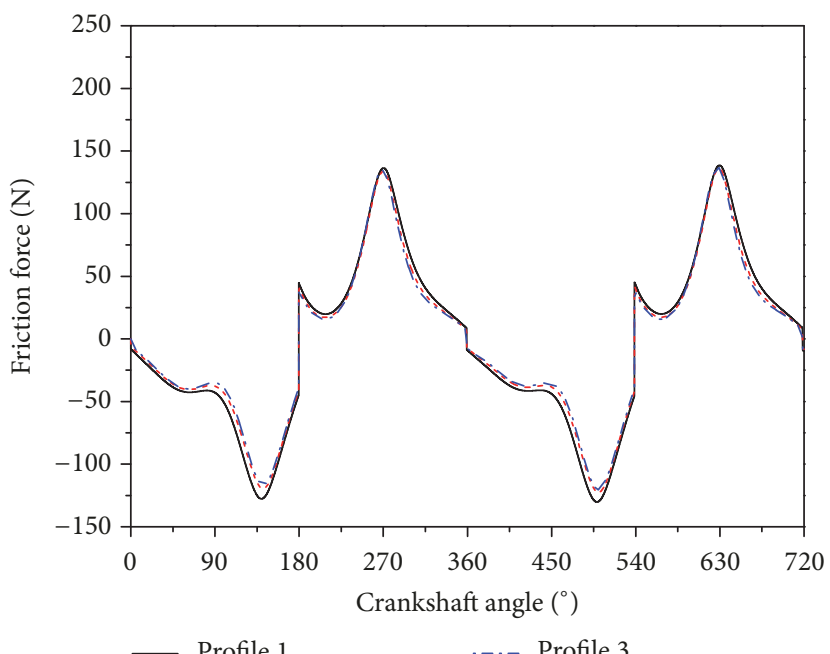

- - - Profile 2

(f) Friction force

Figure 12: Continued. 


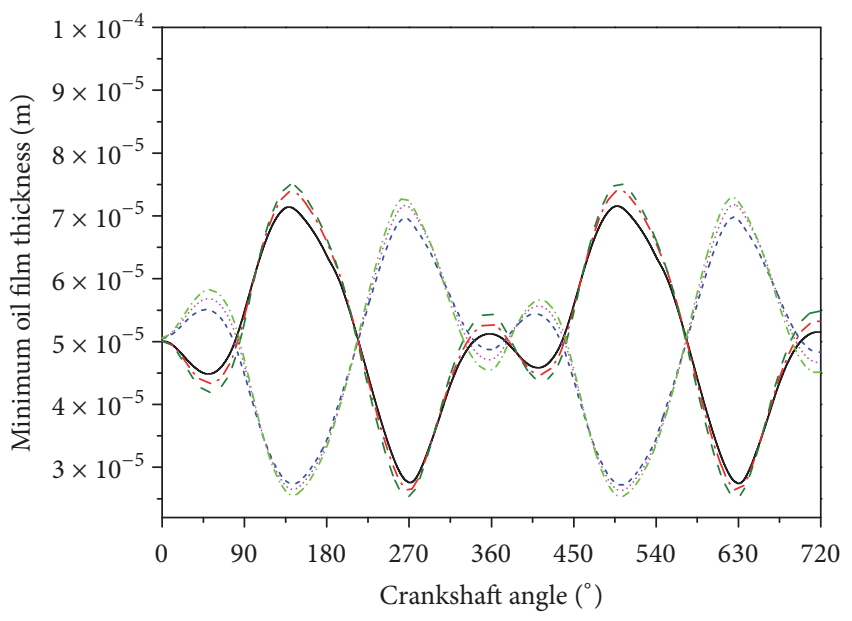

— Major oil film thickness (profile 1)

- - - Minor oil film thickness (profile 1)

...- Major oil film thickness (profile 2)

Minor oil film thickness (profile 2)

- - Major oil film thickness (profile 3)

...- Minor oil film thickness (profile 3)

(g) Minimum oil film thickness

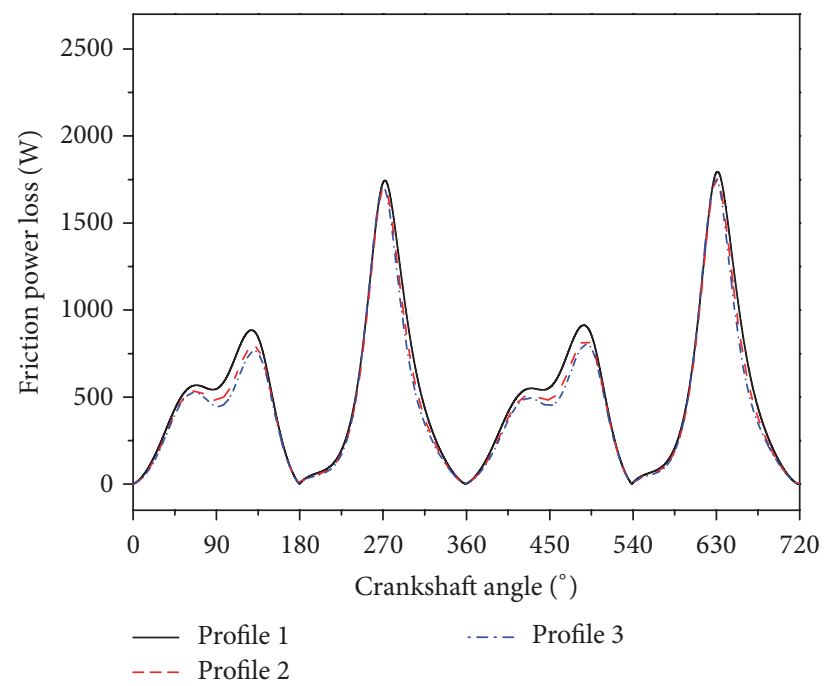

(h) Friction power loss

FIGURE 12: Effect of longitudinal profile on lubrication performance.

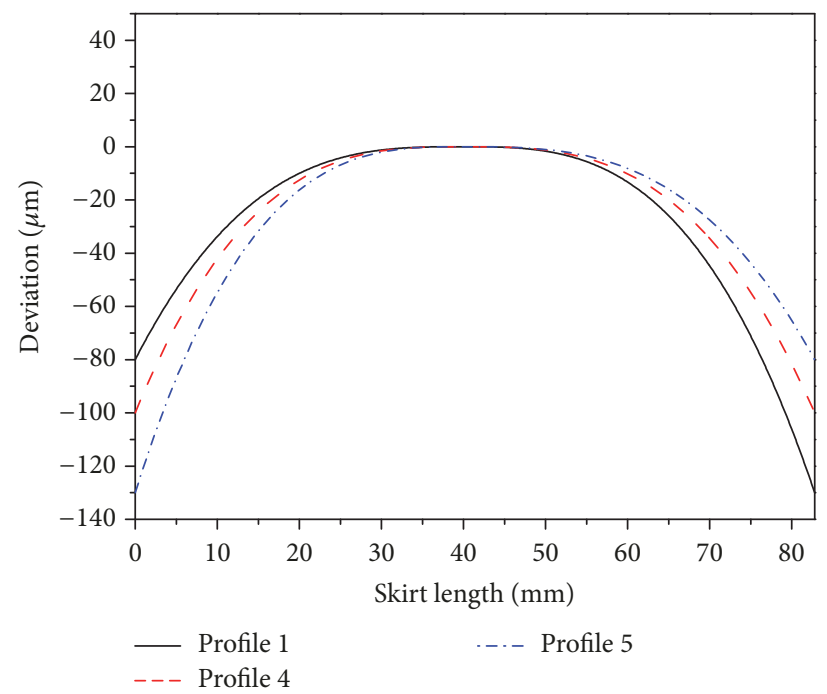

FIgURE 13: Profiles of different radial reduction skirts.

profile 5 are, respectively, $130 \mu \mathrm{m}$ and $80 \mu \mathrm{m}$. Figure 14 shows the effects of different radial reductions of top and bottom skirts on lubrication performance of the piston-cylinder liner system. The secondary displacement and velocity of top skirt of profile 1 decrease, while the secondary displacement and velocity of bottom skirt increase. The change of secondary displacements and velocities is beneficial to decrease the friction force and friction power loss. The maximum piston tilting angle of profile 1 decreases significantly compared to profiles 4 and 5, and the friction power loss decreases, respectively, about $3.7 \%$ and 5\%. In Figure 14, the radial reduction of profile 1 is a more reasonable design parameter.

7.5. Effect of Middle-Convex Point on Lubrication Performance. Figure 15 shows the skirt profiles of different middle-convex points, the middle-convex point of profile 1 is in the middle of piston, that is, $L_{0}=40 \mathrm{~mm}$, the middle-convex point of profile 6 shifts to top skirt, that is, $L_{0}=30 \mathrm{~mm}$, and the 


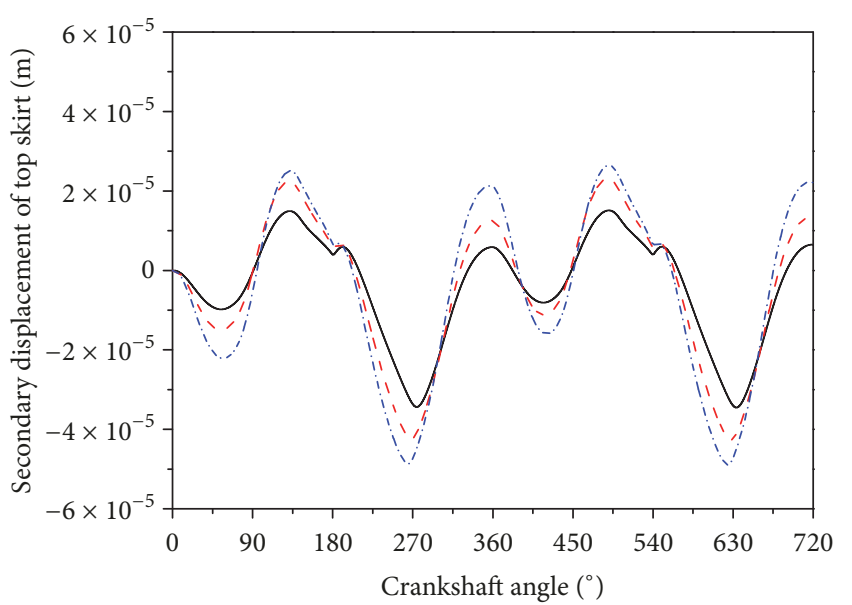

$-e_{t}$ (profile 1)

$--e_{t}$ (profile 4$)$

(a) Secondary displacement of top skirt

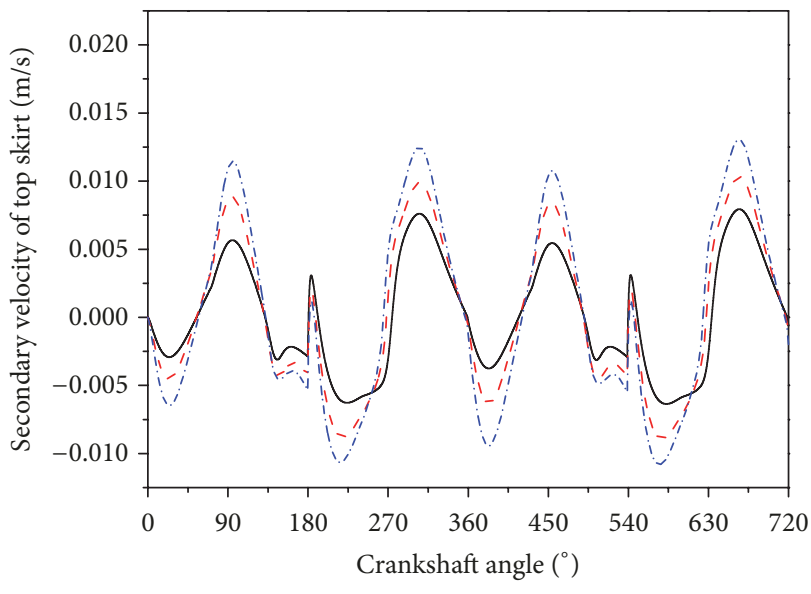

$$
\begin{aligned}
& -e_{t}^{\prime}(\text { profile } 1) \\
& ---e_{t}^{\prime}(\text { profile } 4)
\end{aligned}
$$

(c) Secondary velocity of top skirt

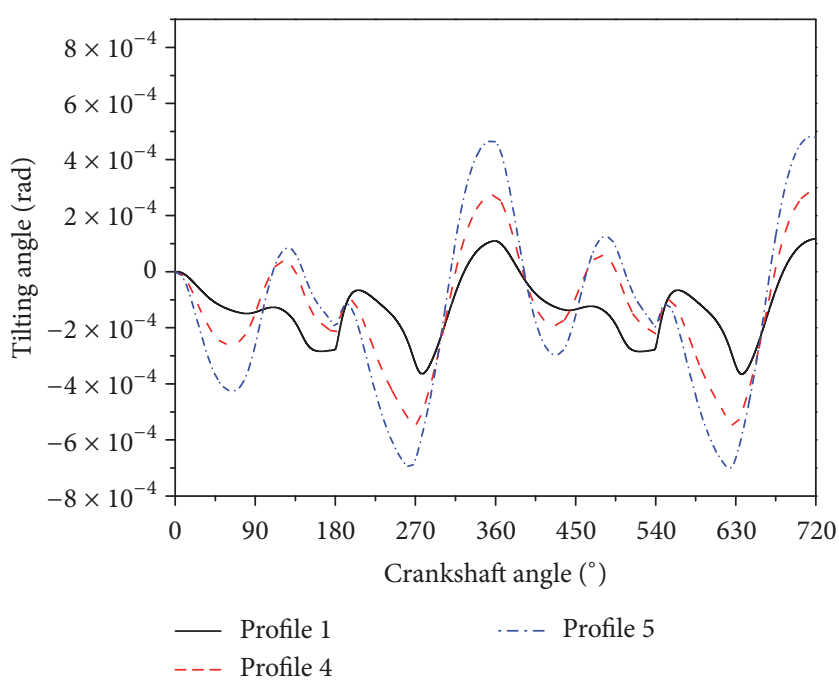

(e) Piston tilting angle

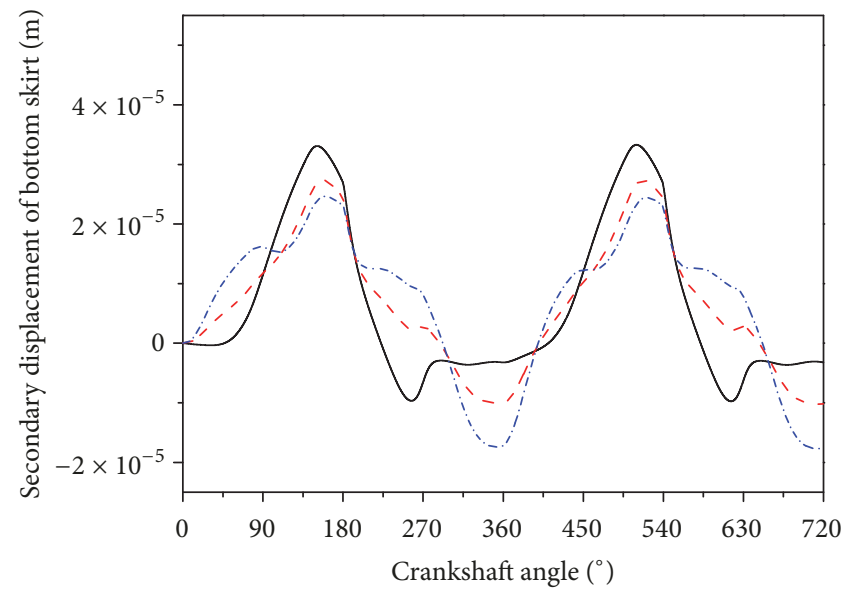

$\begin{array}{lll}- & \left.e_{b} \text { (profile } 1\right) \\ \left.--e_{b} \text { (profile } 4\right) & \cdots & e_{b} \text { (profile 5) }\end{array}$

(b) Secondary displacement of bottom skirt

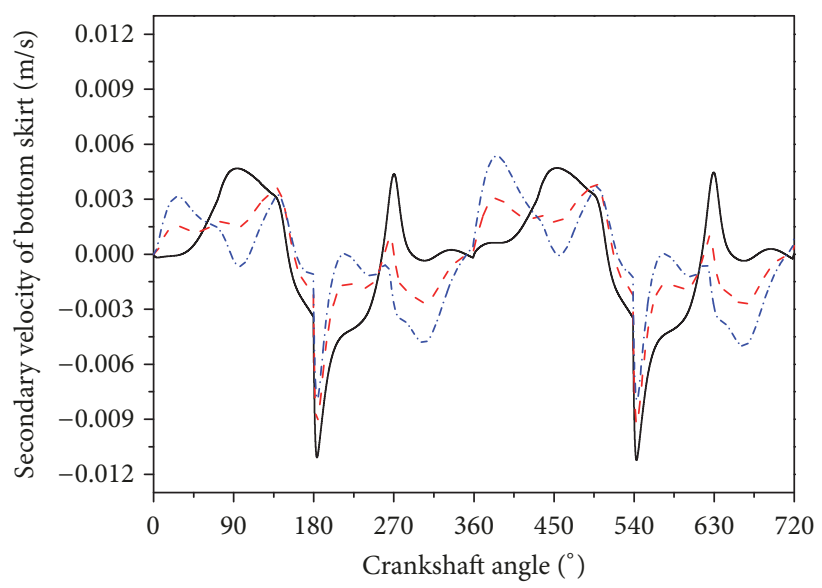

_- Profile 1

(d) Secondary velocity of bottom skirt

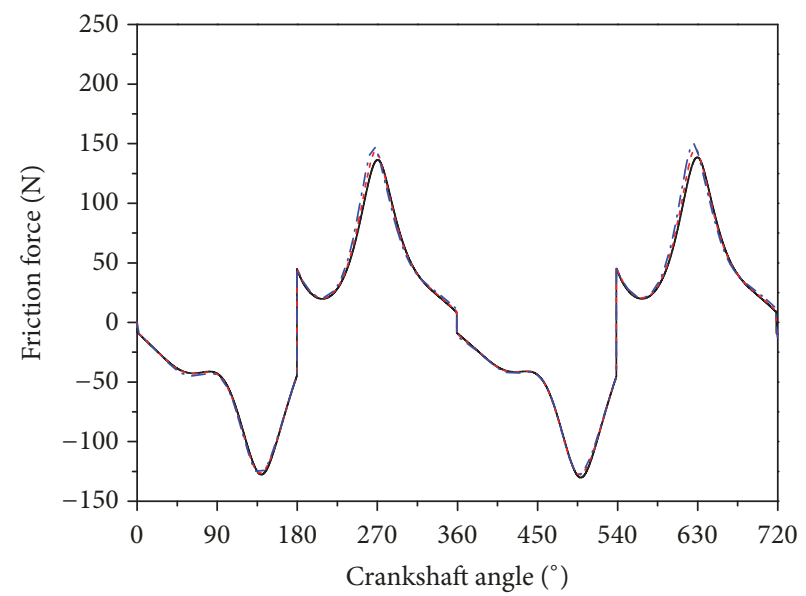

— Profile $1 \quad$...- Profile 5

(f) Friction force

Figure 14: Continued. 


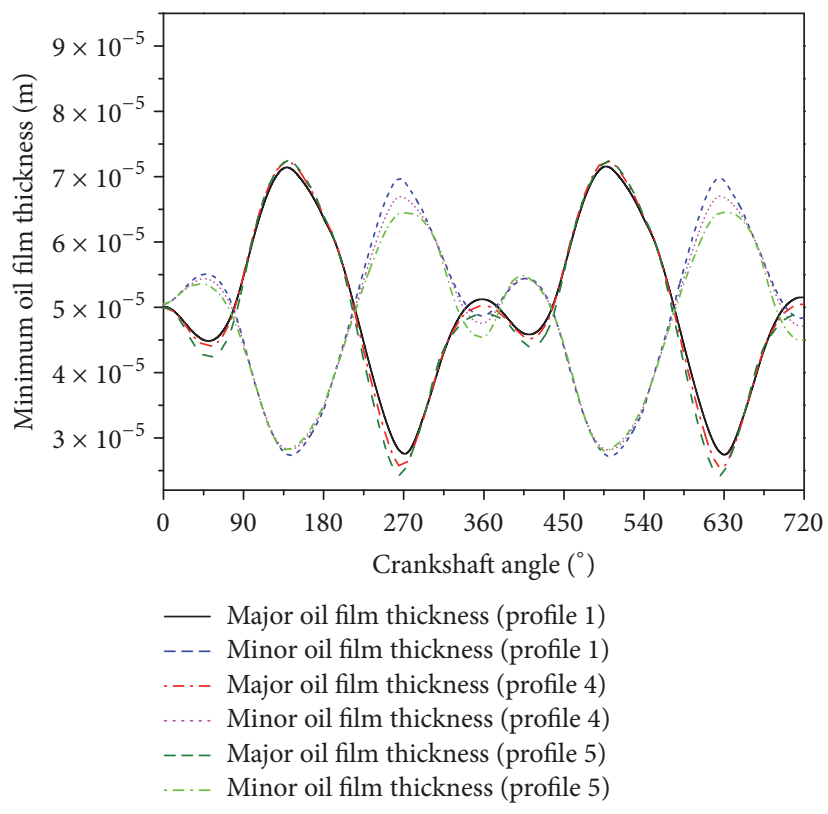

(g) Minimum oil film thickness

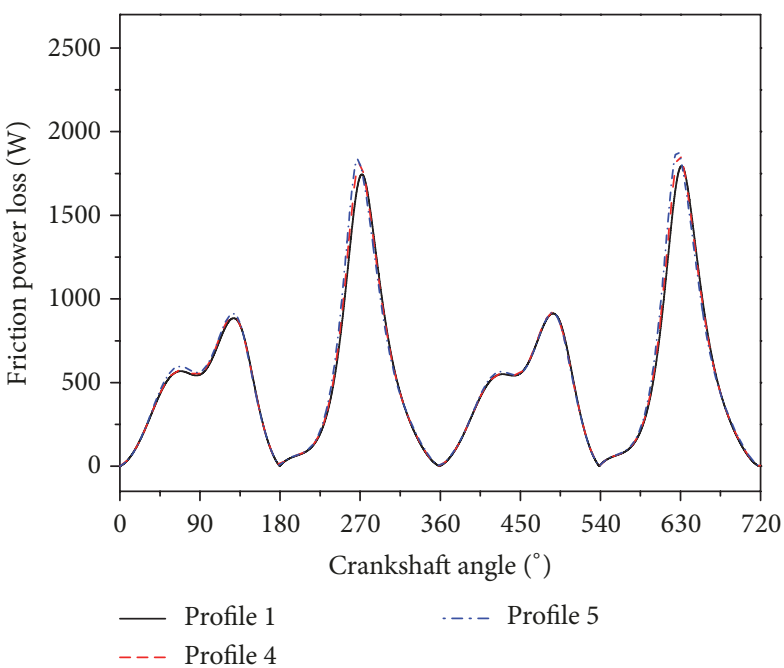

(h) Friction power loss

FIGURE 14: Effect of radial reduction on lubrication performance.

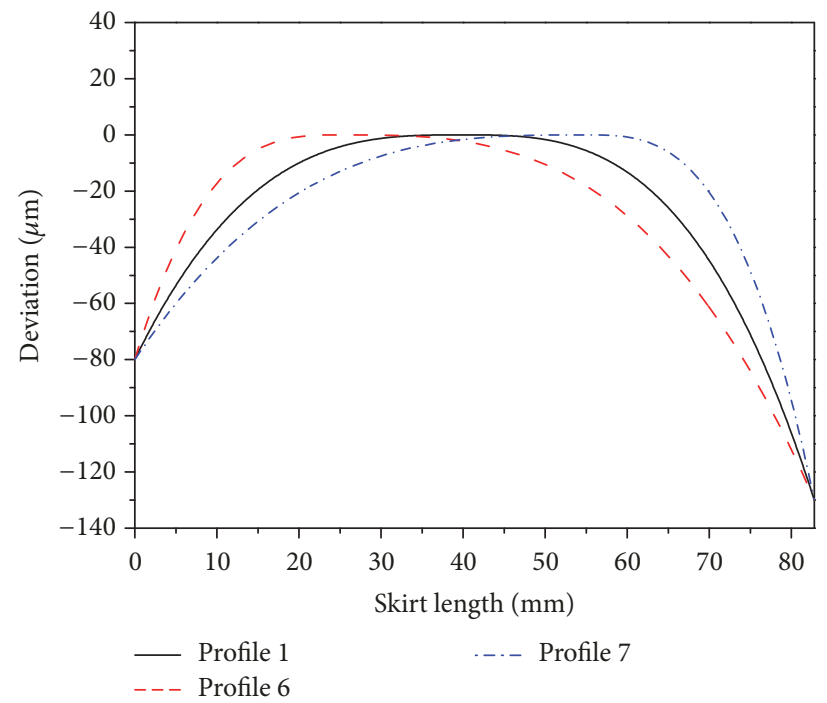

FIGURE 15: Profiles of different middle-convex point skirts.

middle-convex point of profile 7 shifts to bottom skirt, that is, $L_{0}=50 \mathrm{~mm}$. Figure 16 shows the effects of different middle-convex points on lubrication performance of the piston-cylinder liner system. The secondary displacement and velocity of top skirt of the profile 1 increase contrasting with profile 6 , the secondary displacement and velocity of bottom skirt of the profile 1 increase contrasting with profile 7. The maximum piston tilting angle of profile 1 increases contrasting with profile 6 , and the maximum friction force and friction power loss increase slightly. Compared with profile 1, the major minimum oil film thickness of profile 6 decreases obviously for $100^{\circ} \sim 250^{\circ}$ and $460^{\circ} \sim 610^{\circ}$, and the minor minimum oil film thickness of profile 7 decreases obviously for $225^{\circ} \sim 315^{\circ}$ and $585^{\circ} \sim 675^{\circ}$. By considering the secondary displacements, velocities, and minimum oil film thicknesses, profile 1 is more reasonable to obtain better lubrication performance.

7.6. Effect of Horizontal Profile on Lubrication Performance. Figure 17 shows thehorizontal profiles of different ellipticities. 


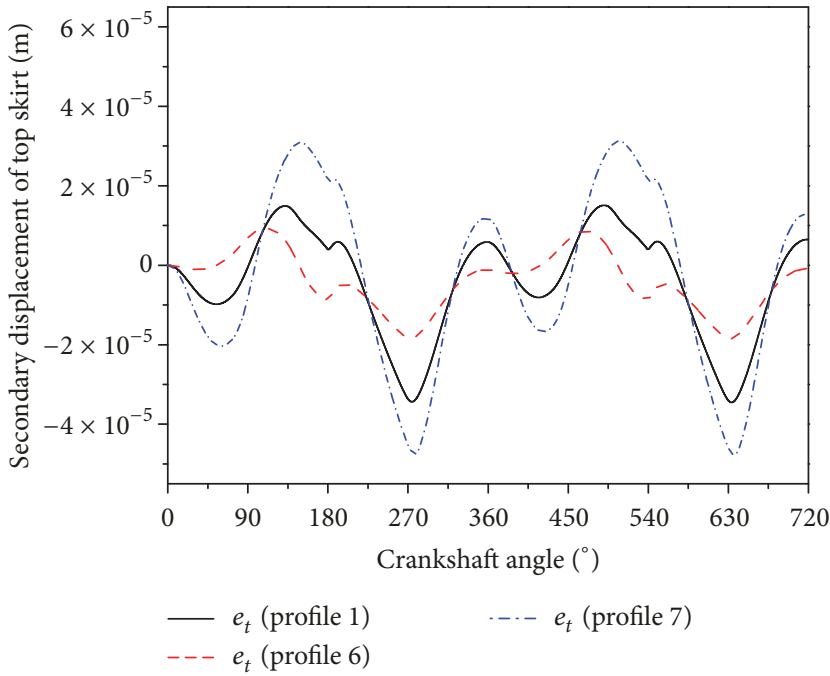

(a) Secondary displacement of top skirt

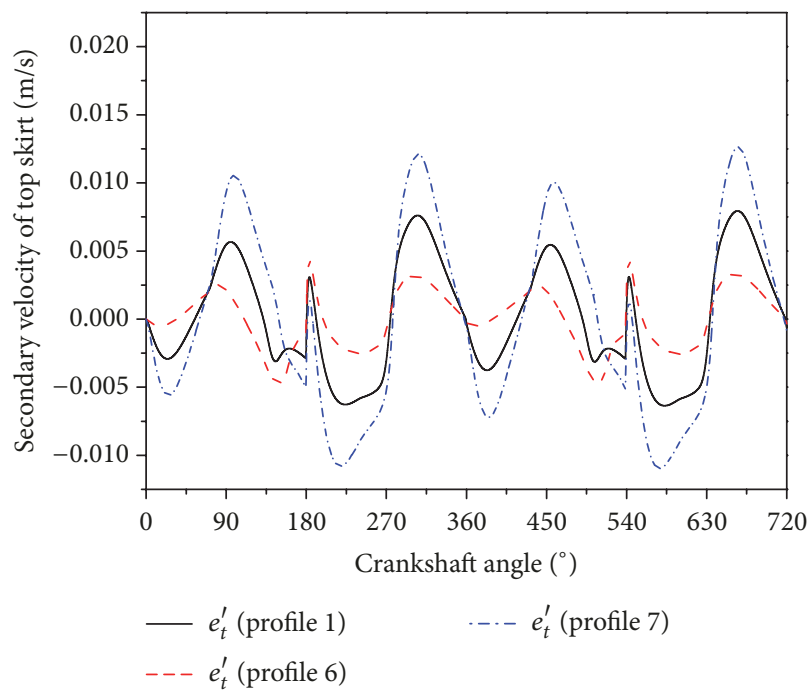

(c) Secondary velocity of top skirt

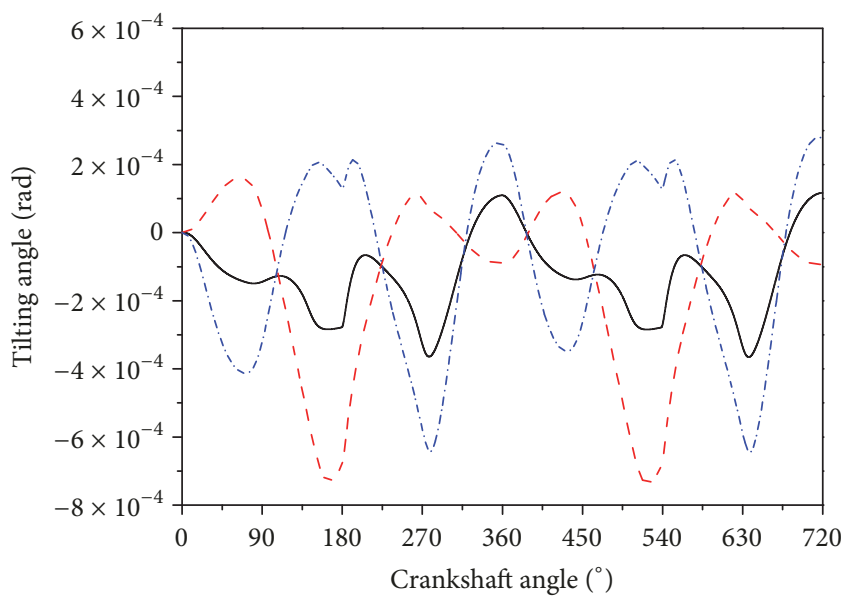

$\begin{array}{ll}\text { — Profile } 1 & \text {-..- Profile } 7\end{array}$

(e) Piston tilting angle

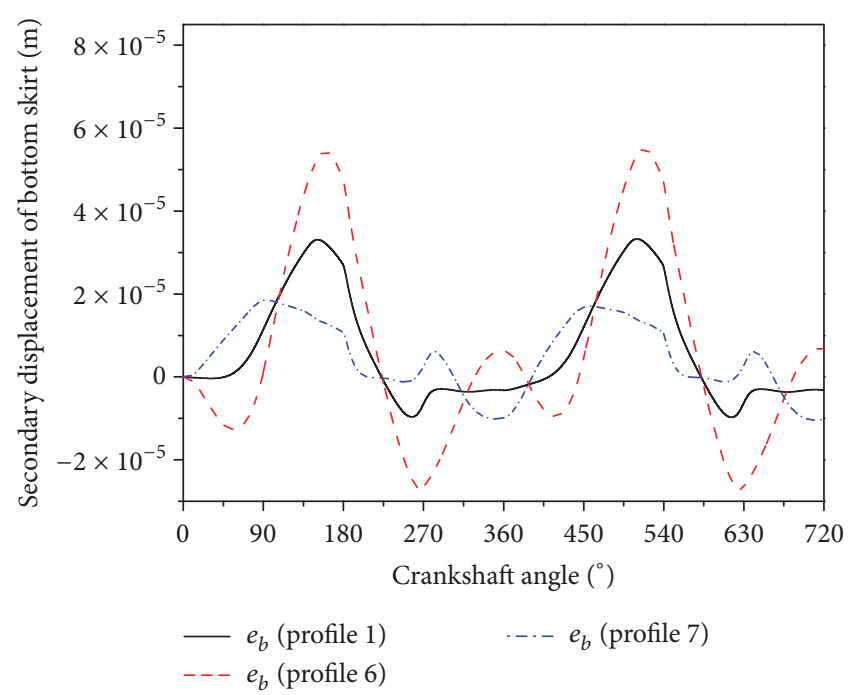

(b) Secondary displacement of bottom skirt

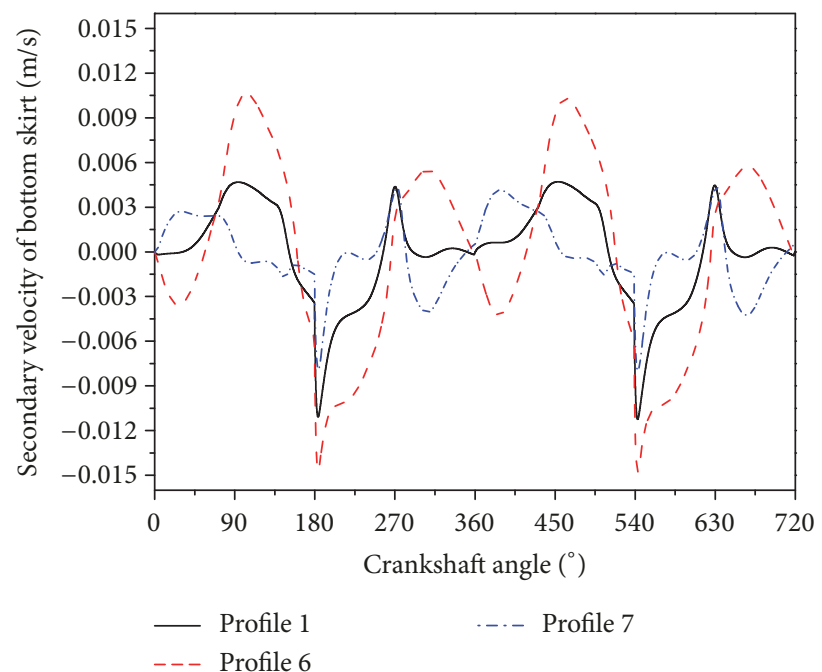

(d) Secondary velocity of bottom skirt

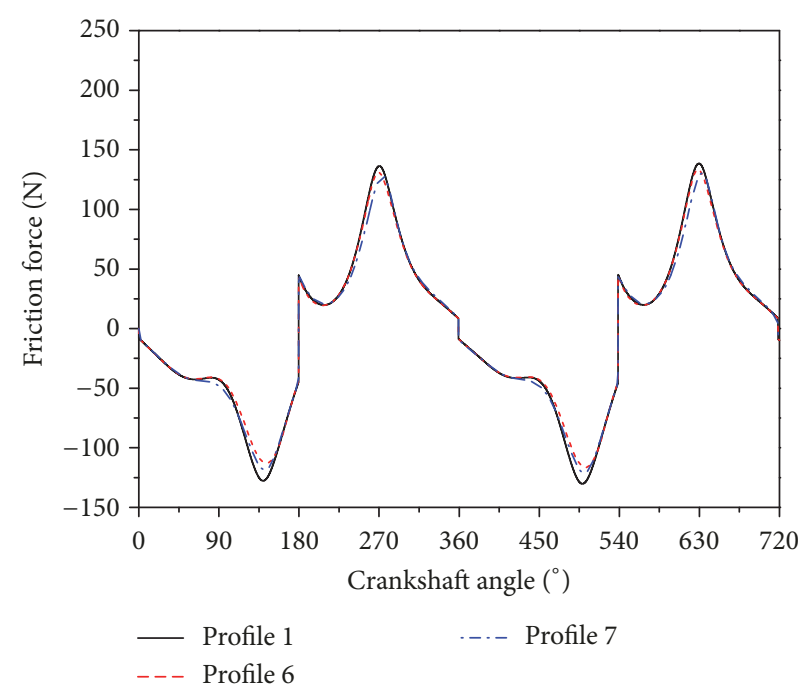

(f) Friction force

FIgURE 16: Continued. 


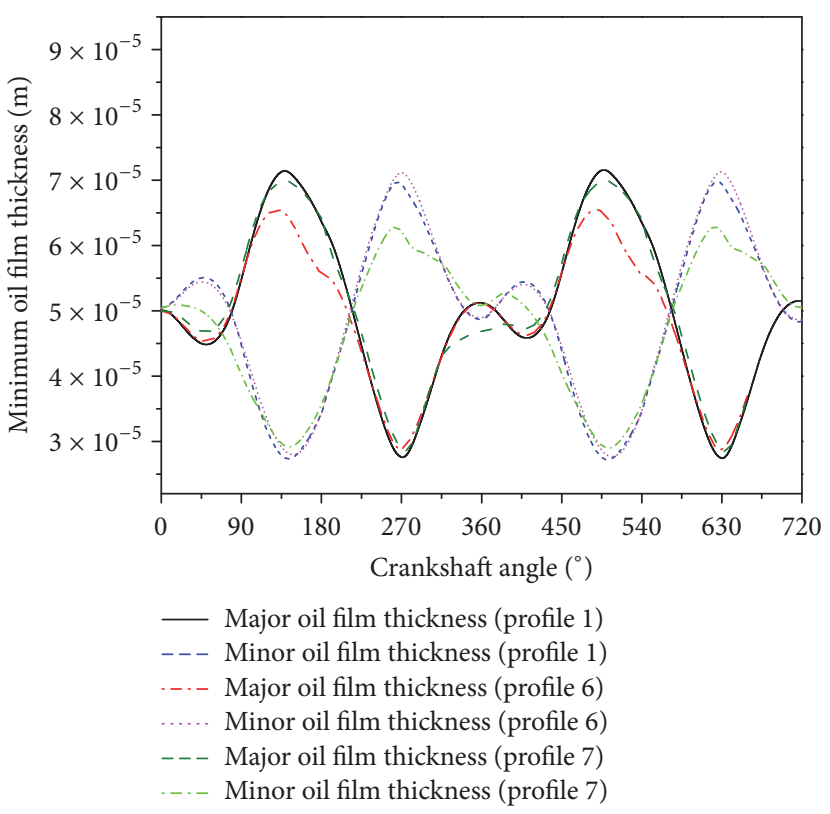

(g) Minimum oil film thickness

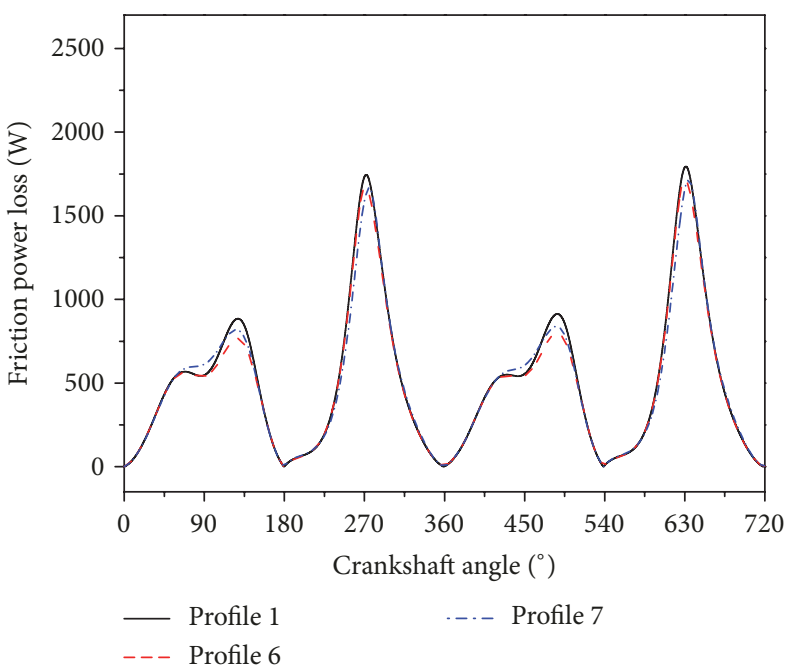

(h) Friction power loss

FIGURE 16: Effect of middle-convex point on lubrication performance.

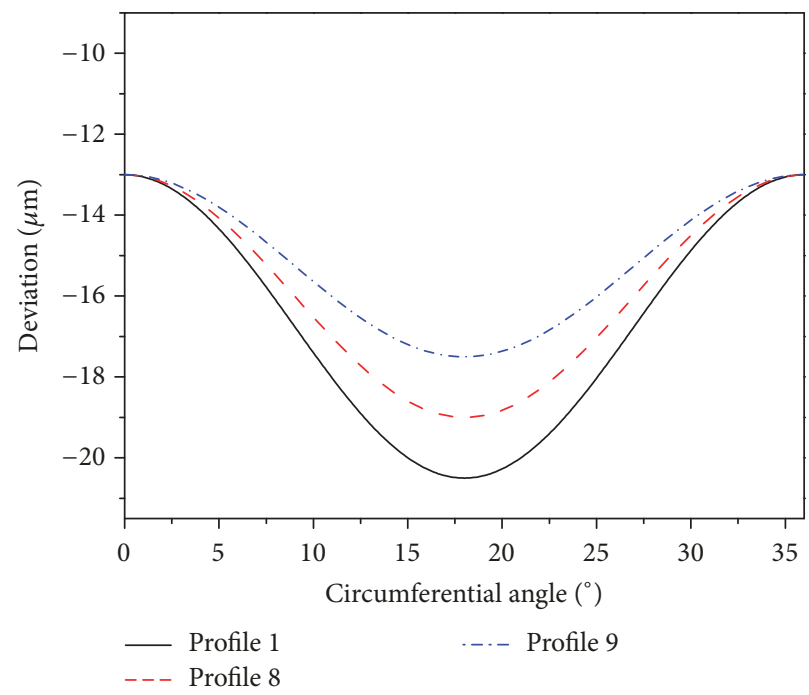

FIGURE 17: Horizontal profiles of different ellipticities.

The ellipticities of top and bottom skirts of profile 1 are, respectively, $90 \mu \mathrm{m}$ and $150 \mu \mathrm{m}$. The ellipticities of profile 8 are both $120 \mu \mathrm{m}$. The ellipticities of profile 9 are, respectively, $150 \mu \mathrm{m}$ and $90 \mu \mathrm{m}$. Figure 18 shows the effects of horizontal profiles of different ellipticities on lubrication performance of the piston-cylinder liner system. Contrasting with profiles 8 and 9 , the secondary displacement and velocity of the top skirt of profile 1 are smaller, and the secondary displacement and velocity of bottom skirt are bigger. The friction force and friction power loss of profile 1 decrease slightly, and the piston tilting angle of profile 1 increases compared with profiles 8 and 9. The results indicate that the lubrication performance is better when the horizontal profile is designed as the smaller ellipticity of top skirt and bigger ellipticity of bottom skirt.

7.7. Effect of the Offset of the Piston Pin Hole on Skirt Lubrication Performance. Figure 19 shows the effect of the 


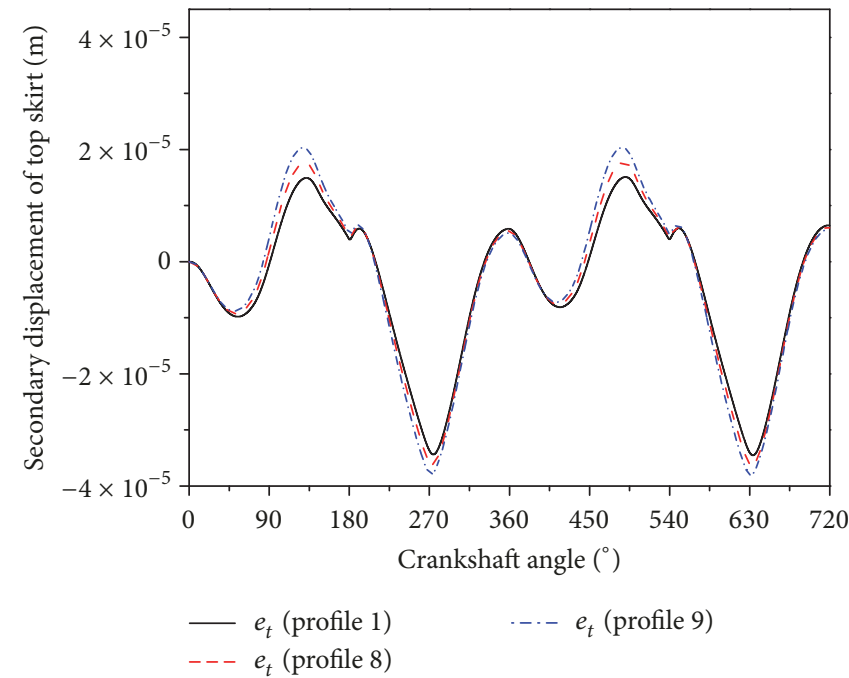

(a) Secondary displacement of top skirt
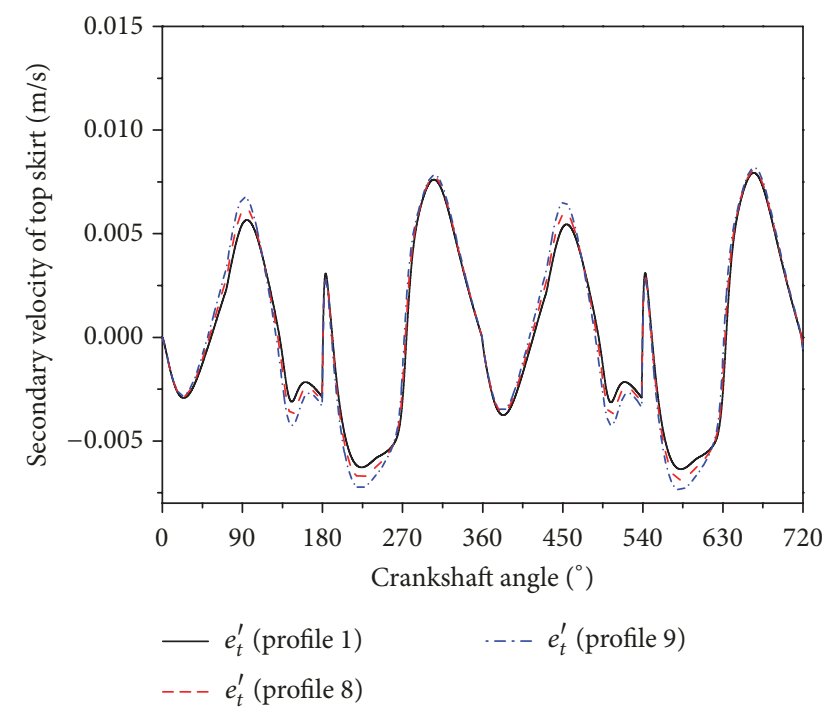

(c) Secondary velocity of top skirt

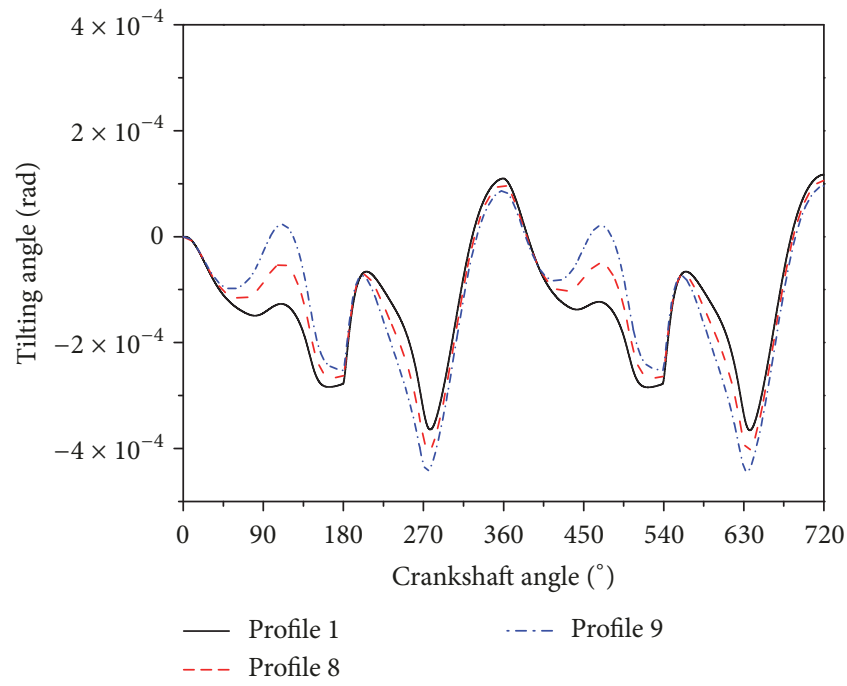

(e) Piston tilting angle

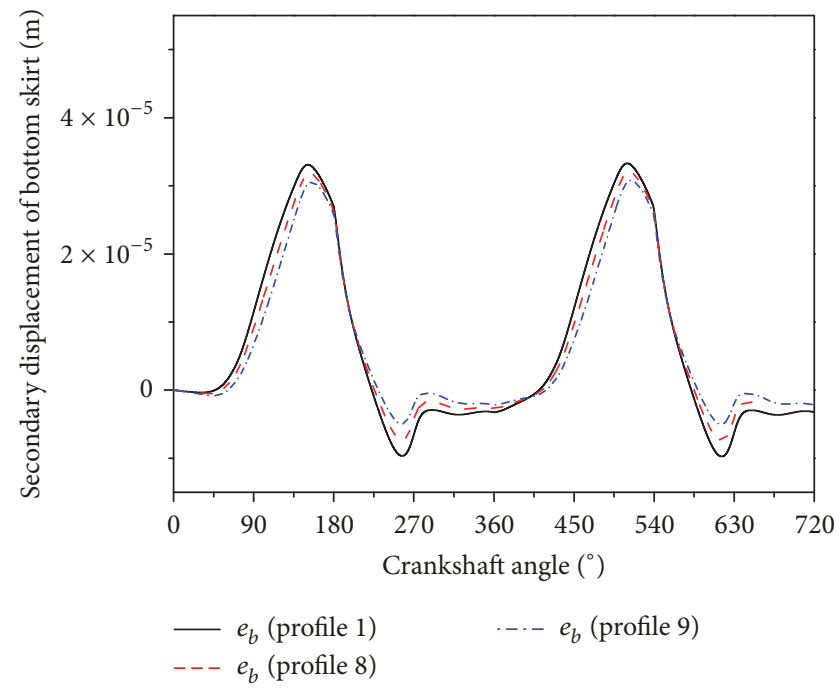

(b) Secondary displacement of bottom skirt

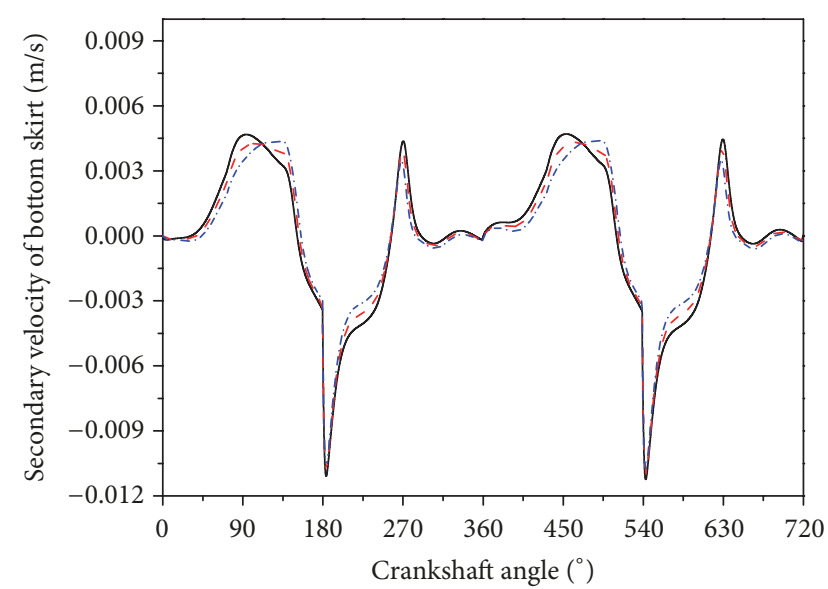

$\begin{array}{ll}\text { — Profile } 1 & \text {-..- Profile } 9\end{array}$

(d) Secondary velocity of bottom skirt

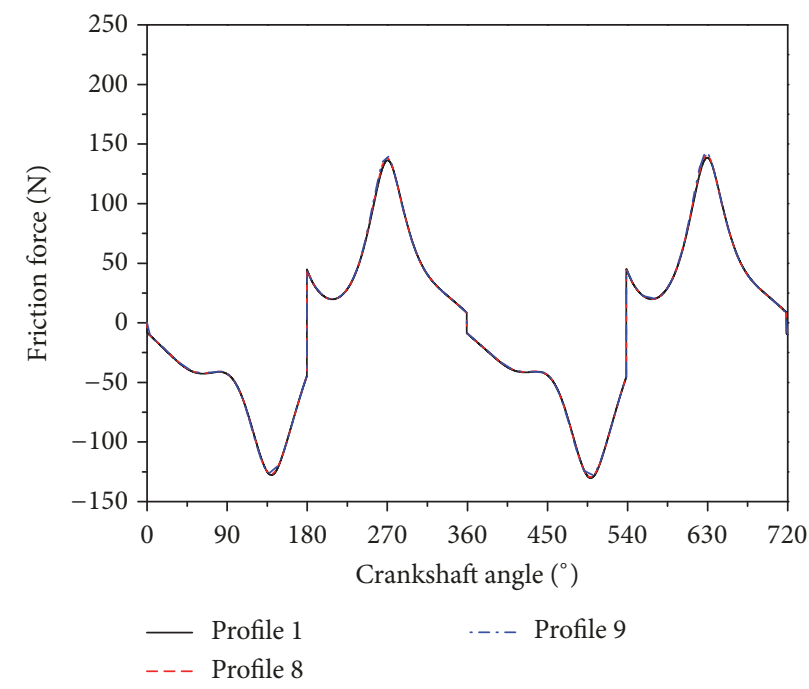

(f) Friction force

Figure 18: Continued. 


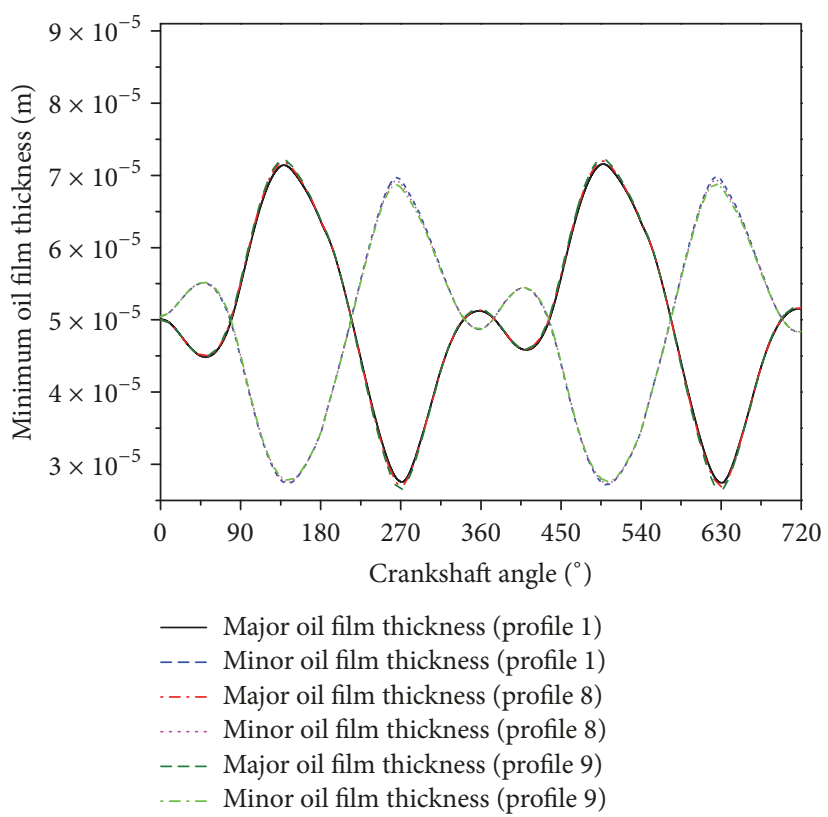

(g) Minimum oil film thickness

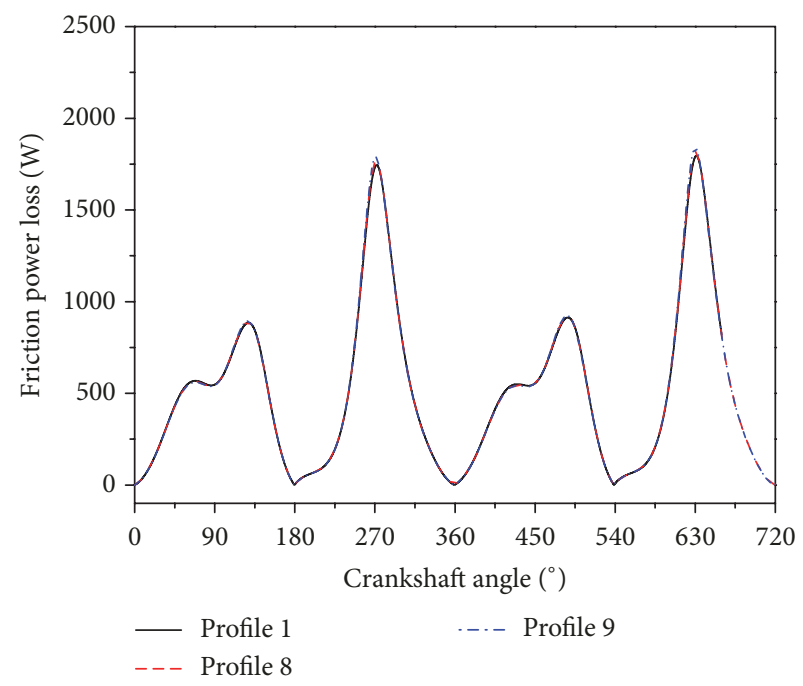

(h) Friction power loss

FIGURE 18: Effect of horizontal profile on lubrication performance.

offset of the piston pin hole on lubrication performance of the piston-cylinder liner system. By contrasting with the nonoffset of piston pin hole, the secondary displacements and velocities of top and bottom piston skirts increase when the piston pin hole shifts to the major thrust side. The trend of curve is contrary when the piston pin hole shifts to the minor thrust side. The reason of the difference is that the position of the piston pin hole determines the swing direction of the piston. Contrasting with the nonoffset of piston pin hole, the maximum displacement of the piston pin center decreases about $8 \%$ while the pin hole shifts to the major thrust side, the maximum friction force decreases about $19.6 \%$, and the friction power loss decreases about $21.6 \%$.

7.8. Effect of Thermal Deformation on Lubrication Performance. Figure 20 shows the temperature distribution nephogram of the piston, and the maximum temperature is $520.11 \mathrm{~K}$ and the minimum temperature is $364.43 \mathrm{~K}$. Figure 21 shows the profiles of piston skirt and cylinder liner before and after thermal deformation, when the piston and cylinder liner are in the expansion stroke. Figure 22 shows the comparison of the secondary motions of piston, piston tilting angles, minimum oil film thicknesses, friction forces, and friction power losses before and after thermal deformation. As Figure 22 shows, the maximum secondary displacement of the piston pin center decreases, and the piston tilting angle increases after thermal deformation. The minimum oil film thickness decreases greatly due to the distortion of the piston skirt profile caused by the thermal deformation, and the friction force and friction power loss increase correspondingly. From Figure 22, the effect of the thermal deformation on lubrication performance of the piston-cylinder liner system is obvious.

\section{Conclusion}

In this paper, JFO boundary condition is employed to describe the rupture and reformation of oil film of the piston-connecting rod system. By considering the inertia of the connecting rod, the influence of the longitudinal and horizontal profiles of piston skirt, the offset of the piston pin, and the thermal deformation on the secondary motion and lubrication performance is investigated. The results are as follows.

(1) Contrasting with the Reynolds boundary condition, the secondary motion of the piston under JFO boundary condition has a significant difference. The tribological performance of the piston-cylinder liner system under JFO boundary condition is closer to the realistic condition. By considering the connecting rod inertia, based on JFO boundary condition, the piston dynamic behaviors and mixed-lubrication performance of piston-cylinder liner system are analyzed. The results show that the effects of the connecting rod inertia, piston skirt profile, and thermal deformation on piston secondary motion and lubrication performance of piston skirt are significant, and the effect of elastic deformation is small within the selected data set.

(2) When the piston skirt profile is designed as parabola, the smaller the radial reduction of top skirt and the bigger the radial reduction of bottom skirt, the smaller the ellipticity of top skirt and the bigger the ellipticity of bottom skirt; the lubrication performance of piston skirt is superior. 


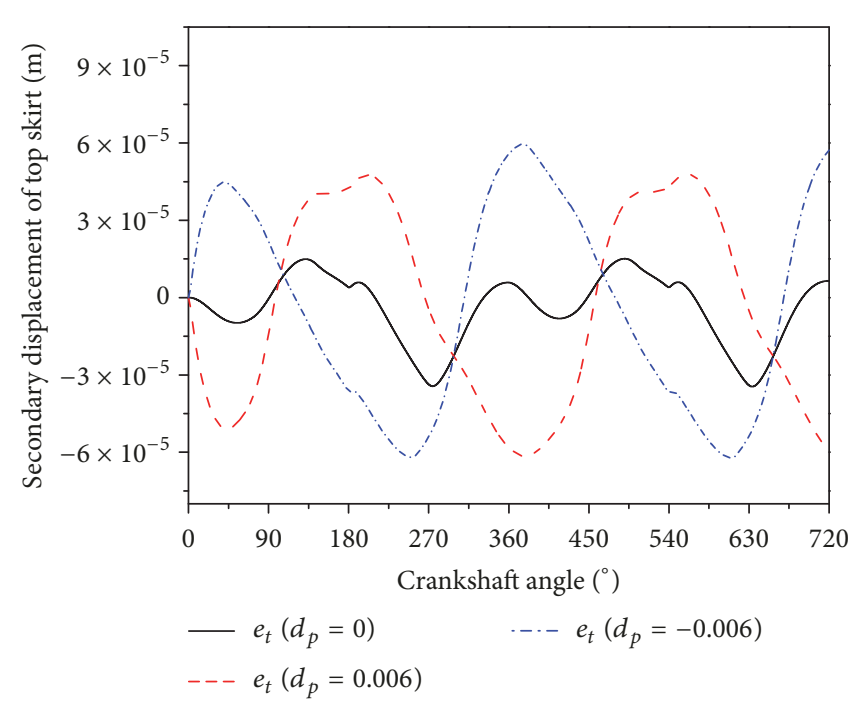

(a) Secondary displacement of top skirt

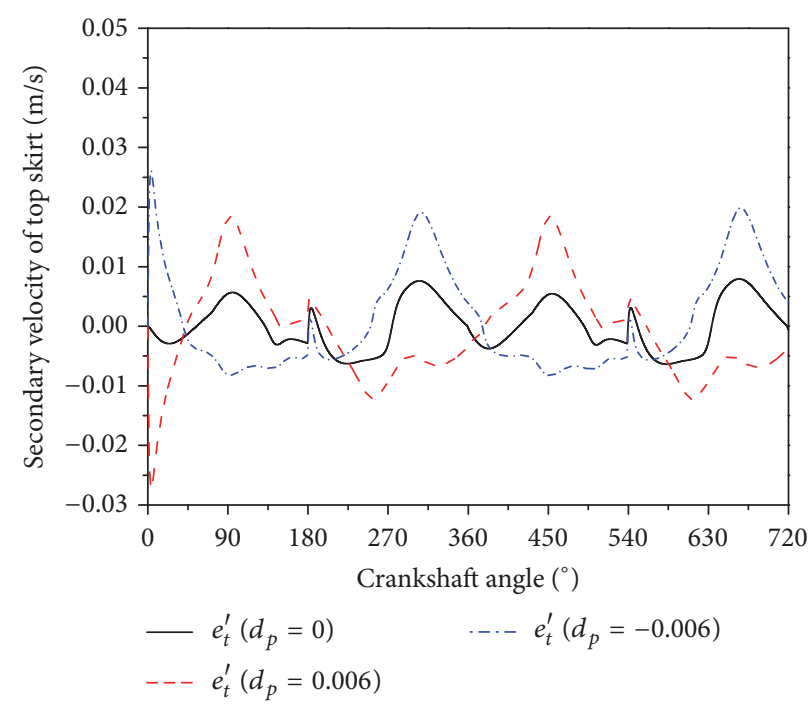

(c) Secondary velocity of top skirt

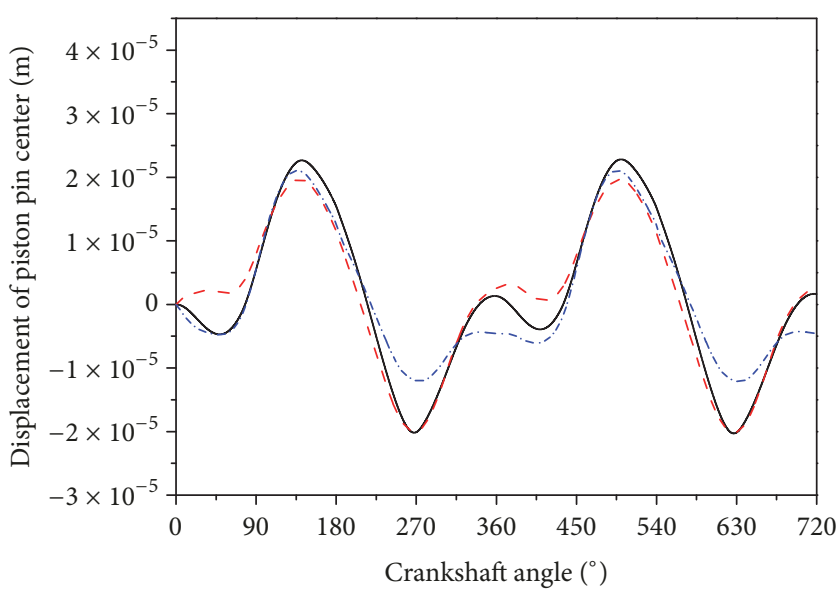

$$
\begin{array}{ll}
-d_{p} & =0 \\
---d_{p}=0.006 & -. \cdot d_{p}=-0.006
\end{array}
$$

(e) Displacement of piston pin center

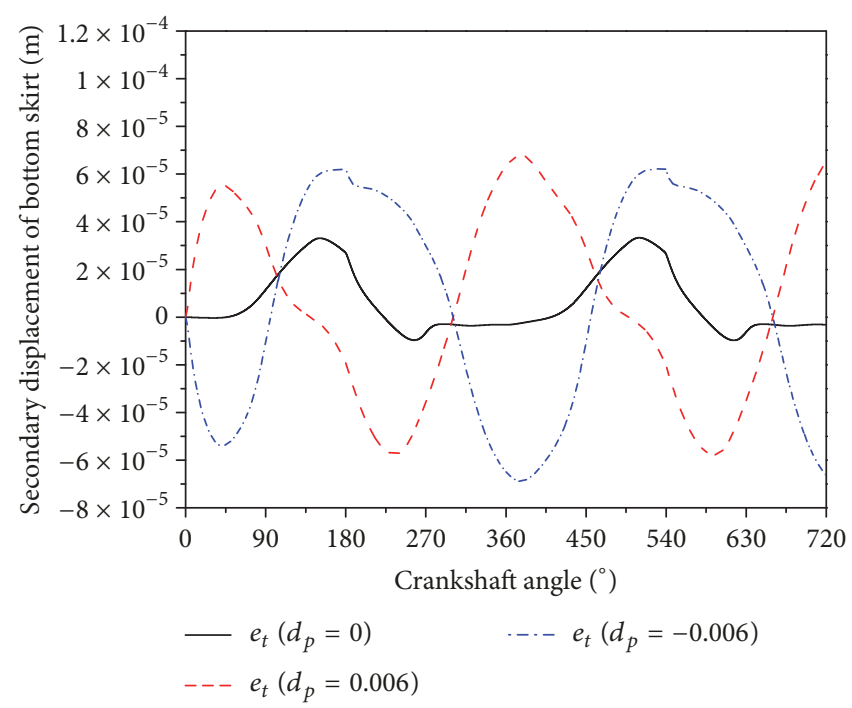

(b) Secondary displacement of bottom skirt

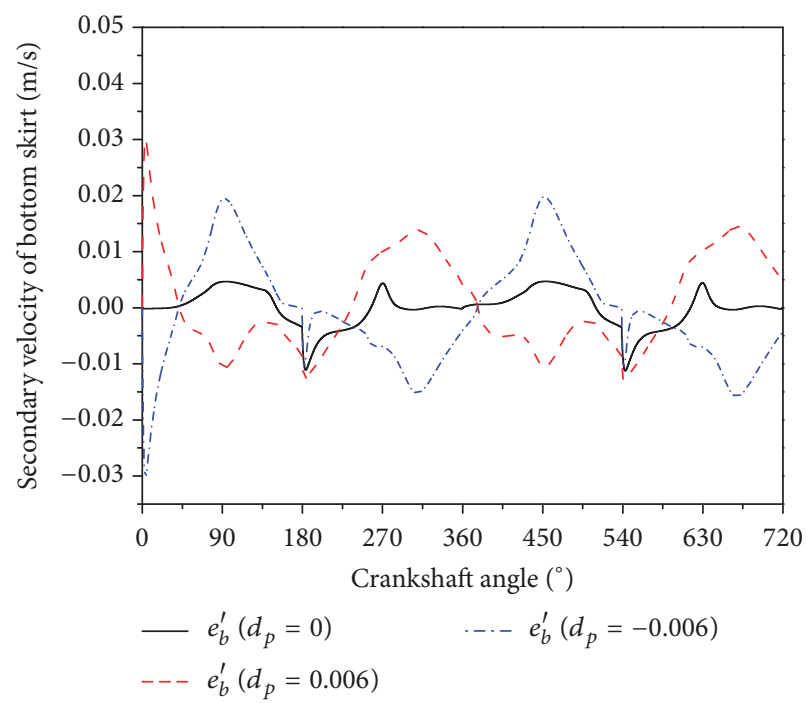

(d) Secondary velocity of bottom skirt

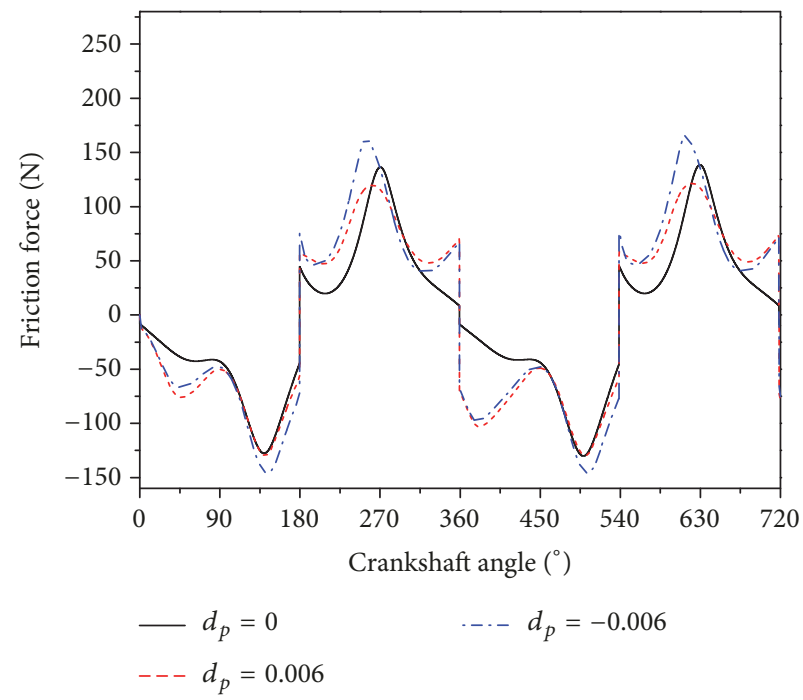

(f) Friction force

Figure 19: Continued. 


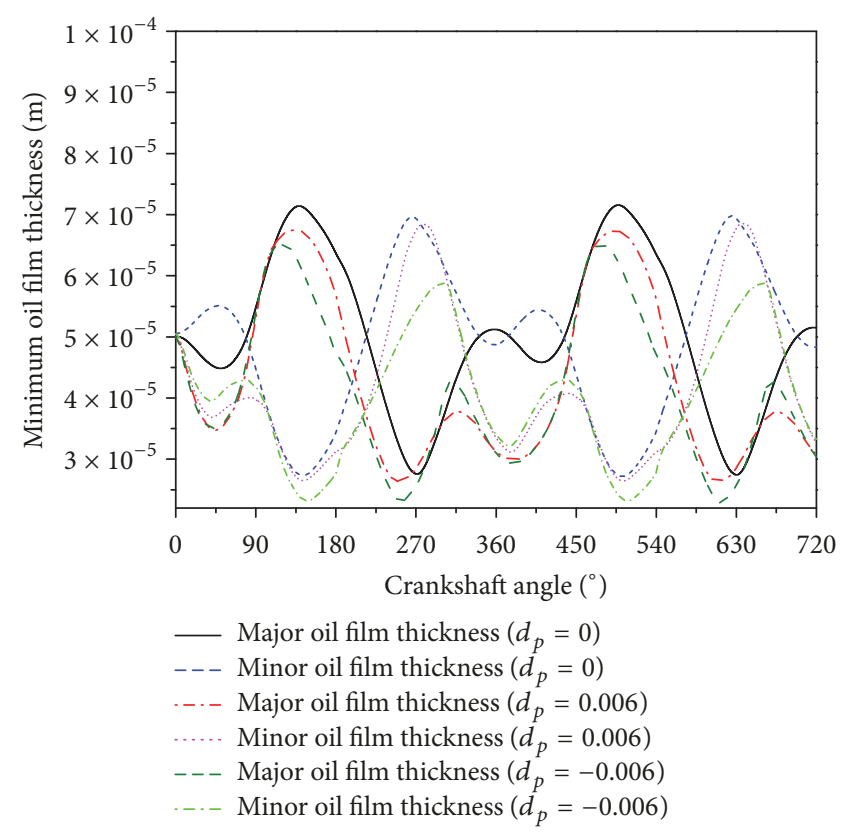

(g) Minimum oil film thickness

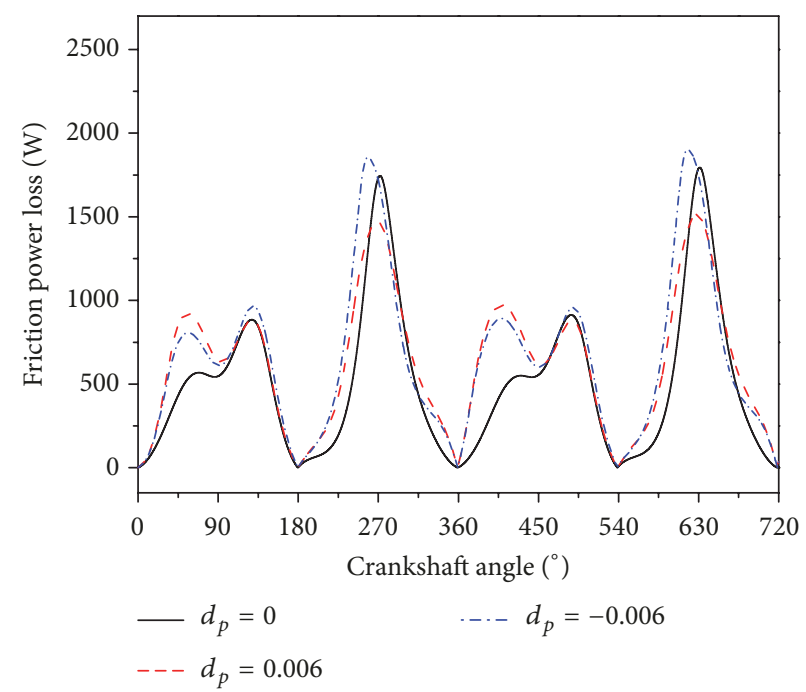

(h) Friction power loss

FIGURE 19: Effect of piston pin offset on skirt lubrication performance.

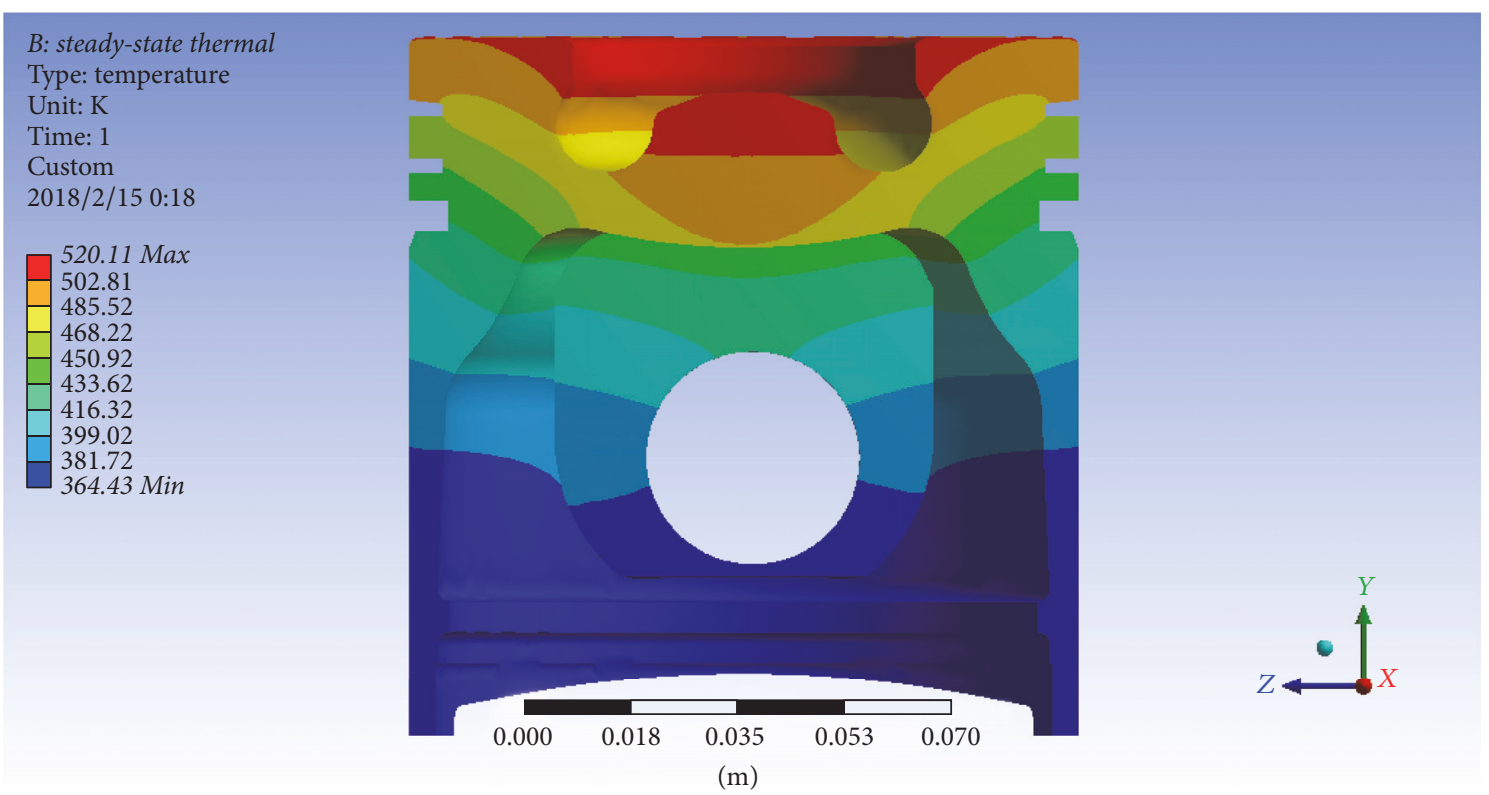

FIGURE 20: Distribution nephogram of the piston temperature.

(3) When the piston pin slightly shifts to the major thrust side, the secondary displacement and velocity of piston increase, the friction force and friction power loss decrease, and the friction characteristics of piston skirt are better.

(4) By considering thermal deformation of the piston skirt, the minimum oil film thickness obviously decreases; furthermore, the piston tilting angle, friction force, and friction power loss significantly increase. The influence of the thermal deformation of the piston skirt on the lubrication performance is a nonnegligible factor, so further research on the thermal deformation needs to be conducted in the following work. 


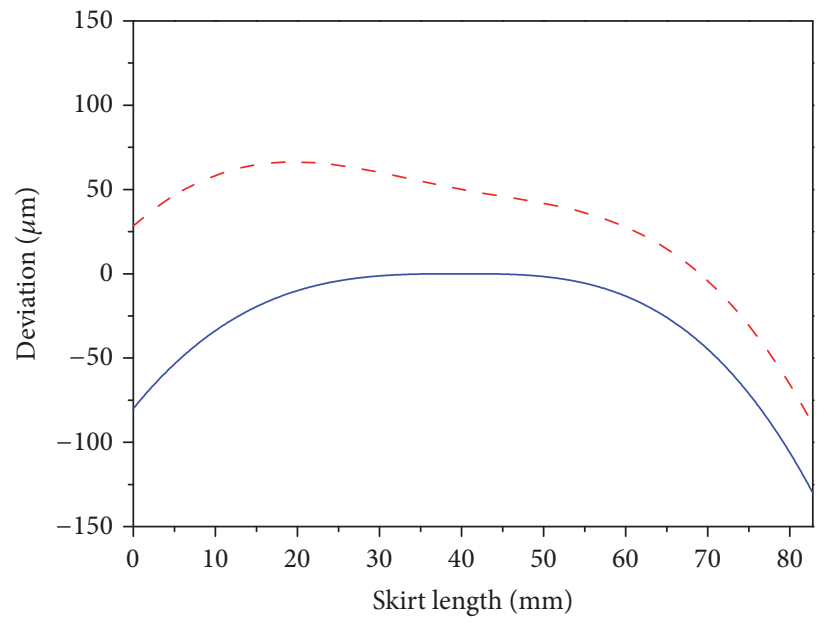

- Nondeformation

--- Thermal deformation

(a) Profiles of piston skirt

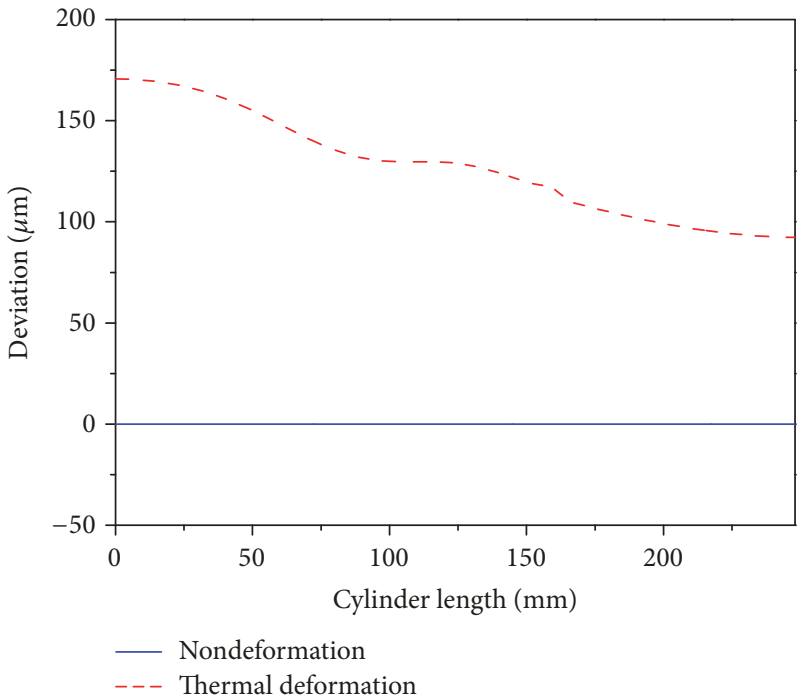

(b) Profiles of cylinder liner

FIGURE 21: Profiles of piston skirt and cylinder liner before and after thermal deformation.

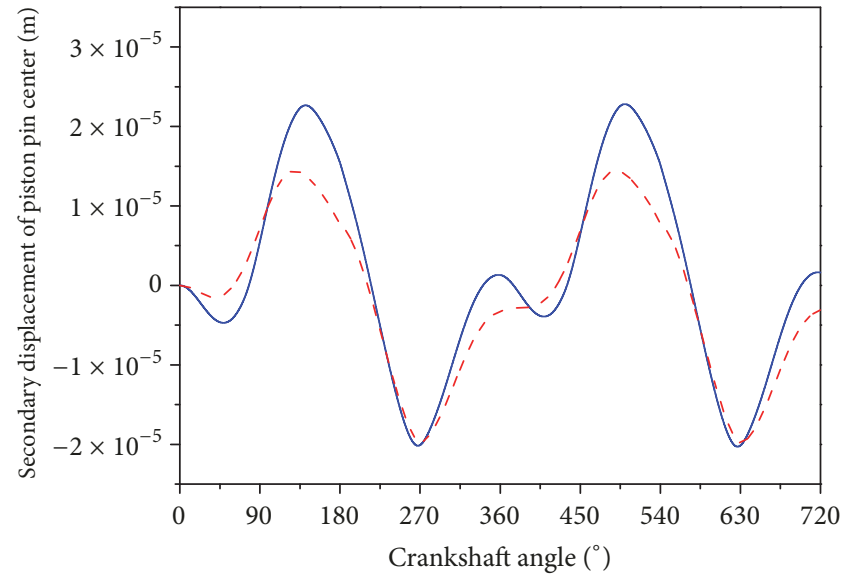

_ Nondeformation

- - - Thermal deformation

(a) Secondary displacement of piston pin center

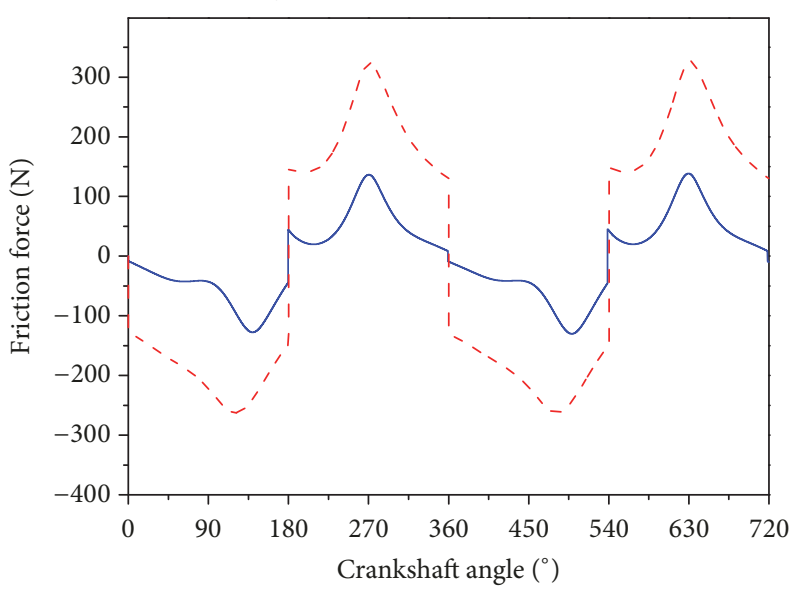

- Nondeformation

- - Thermal deformation

(c) Friction force

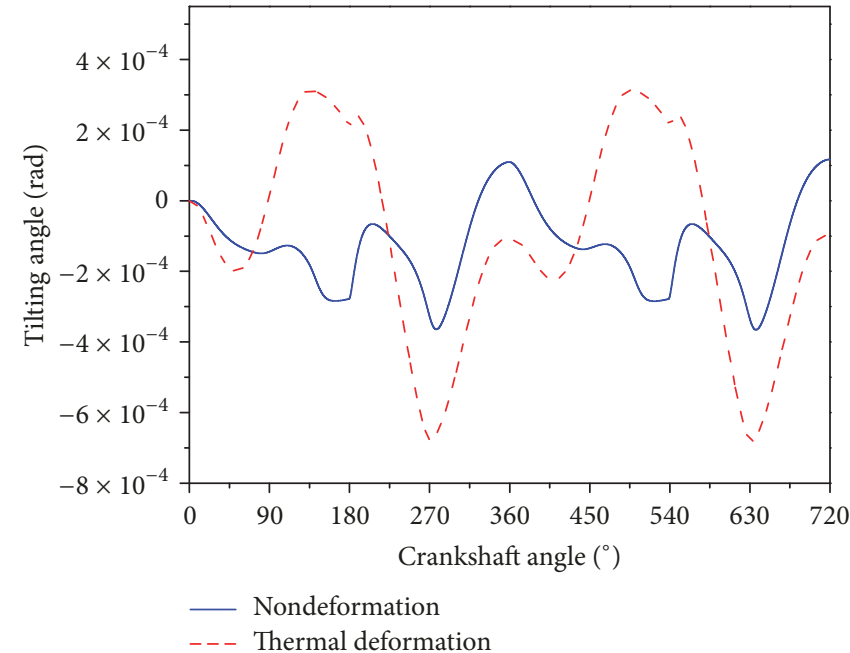

(b) Piston tilting angle

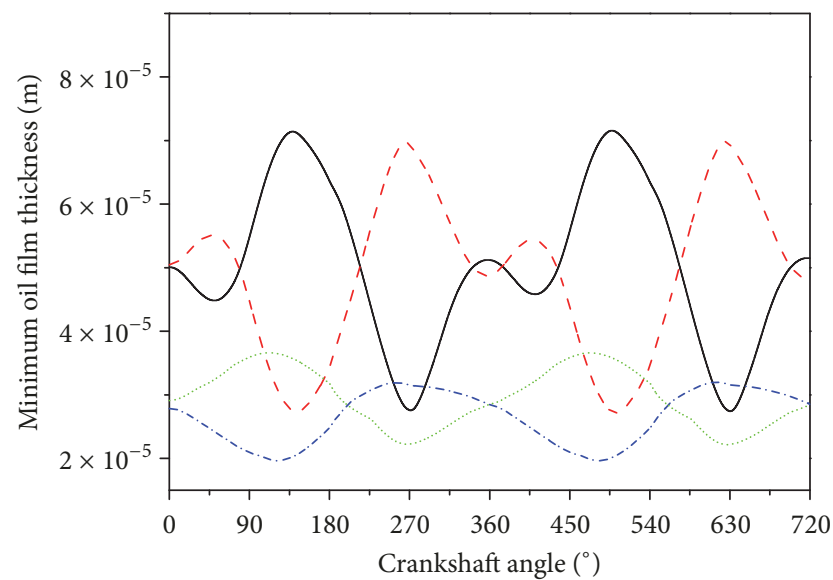

- Major oil film thickness (nondeformation)

- - - Minor oil film thickness (nondeformation)

. - - Major oil film thickness (thermal deformation) Minor oil film thickness (thermal deformation)

(d) Minimum oil film thickness

FIgURE 22: Continued. 


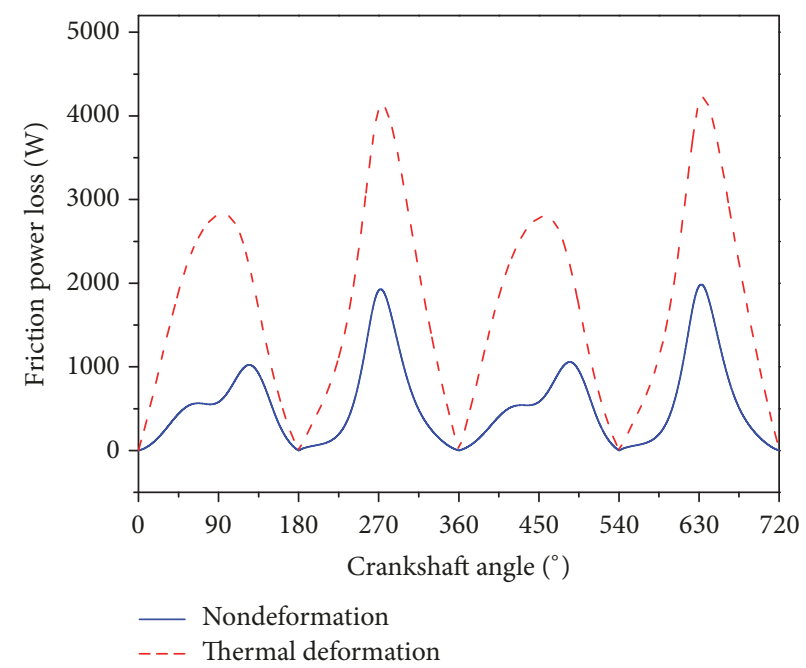

(e) Friction power loss

FIGURE 22: Effect of thermal deformation on lubrication performance.

\section{Conflicts of Interest}

The authors declare that there are no conflicts of interest regarding the publication of this paper.

\section{Acknowledgments}

The research was supported by National Natural Science Foundation of China (Grant no. 51775428), Open Project of State Key Laboratory of Digital Manufacturing Equipment and Technology (Grant no. DMETKF2017014), Natural Science Foundation of Shaanxi Province of China (Grant no. 2014JM2-5082), and Scientific Research Program of Shaanxi Provincial Education Department of China (Grant no. 15JS068).

\section{References}

[1] S. H. Mansouri and V. W. Wong, "Effects of piston design parameters on piston secondary motion and skirt-liner friction," Proceedings of the Institution of Mechanical Engineers, Part J: Journal of Engineering Tribology, vol. 219, no. 6, Article ID J03604, pp. 435-449, 2005.

[2] G. A. Livanos and N. P. Kyrtatos, "Friction model of a marine diesel engine piston assembly," Tribology International, vol. 40, no. 10-12, pp. 1441-1453, 2007.

[3] C. Kirner, J. Halbhuber, B. Uhlig, A. Oliva, S. Graf, and G. Wachtmeister, "Experimental and simulative research advances in the piston assembly of an internal combustion engine," Tribology International, vol. 99, pp. 159-168, 2016.

[4] Y. Wang, Y. Li, J. Yang, C. Sun, K. Liu, and R. Feng, "Effects of anodic oxidation for combustion chamber on heat transfer of the piston in an aero-engine," Experimental Heat Transfer, vol. 30, no. 1, pp. 46-65, 2017.

[5] H. Shahmohamadi, M. Mohammadpour, R. Rahmani, H. Rahnejat, C. P. Garner, and S. Howell-Smith, "On the boundary conditions in multi-phase flow through the piston ring-cylinder liner conjunction," Tribology International, vol. 90, pp. 164-174, 2015.

[6] J. Zhang and Y. Meng, "Direct observation of cavitation phenomenon and hydrodynamic lubrication analysis of textured surfaces," Tribology Letters, vol. 46, no. 2, pp. 147-158, 2012.

[7] F. M. Meng, Y. Y. Zhang, Y. Z. Hu, and H. Wang, "Thermoelasto-hydrodynamic lubrication analysis of piston skirt considering oil film inertia effect," Tribology International, vol. 40, no. 7, pp. 1089-1099, 2007.

[8] Y.-C. Tan and Z. M. Ripin, "Analysis of piston secondary motion," Journal of Sound and Vibration, vol. 332, no. 20, pp. 5162-5176, 2013.

[9] Y.-C. Tan and Z. M. Ripin, "Technique to determine instantaneous piston skirt friction during piston slap," Tribology International, vol. 74, pp. 145-153, 2014.

[10] H. Murakami, N. Nakanishi, N. Ono, and T. Kawano, "New three-dimensional piston secondary motion analysis method coupling structure analysis and multi body dynamics analysis," SAE International Journal of Engines, vol. 5, no. 1, pp. 42-50, 2012.

[11] F. M. Meng, X. F. Wang, T. T. Li, and Y. P. Chen, "Influence of cylinder liner vibration on lateral motion and tribological behaviors for piston in internal combustion engine," Proceedings of the Institution of Mechanical Engineers, Part J: Journal of Engineering Tribology, vol. 229, no. 2, pp. 151-167, 2015.

[12] S. Narayan, "Effects of Various Parameters on Piston Secondary Motion," SAE Technical Papers, vol. 2015-, no. March, 2015.

[13] P. Obert, T. Müller, H.-J. Füßer, and D. Bartel, “The influence of oil supply and cylinder liner temperature on friction, wear and scuffing behavior of piston ring cylinder liner contacts-a new model test," Tribology International, vol. 94, pp. 306-314, 2016.

[14] R. Mazouzi, A. Kellaci, and A. Karas, "Effects of piston design parameters on skirt-liner dynamic behavior," Industrial Lubrication and Tribology, vol. 68, no. 2, pp. 250-258, 2016.

[15] C. Fang, X. Meng, and Y. Xie, "A piston tribodynamic model with deterministic consideration of skirt surface grooves," Tribology International, vol. 110, pp. 232-251, 2017. 
[16] B. Littlefair, M. De La Cruz, S. Theodossiades et al., "Transient tribo-dynamics of thermo-elastic compliant high-performance piston skirts," Tribology Letters, vol. 53, no. 1, pp. 51-70, 2014.

[17] P. D. McFadden and S. R. Turnbull, "A study of the secondary piston motion arising from changes in the piston skirt profile using a simplified piston skirt model," Proceedings of the Institution of Mechanical Engineers, Part C: Journal of Mechanical Engineering Science, vol. 227, no. 1, pp. 38-47, 2013.

[18] O. Gunelsu and O. Akalin, "The effects of piston skirt profiles on secondary motion and friction," Journal of Engineering for Gas Turbines and Power, vol. 136, no. 6, Article ID 062503, 2014.

[19] Z. He, W. Xie, G. Zhang, Z. Hong, and J. Zhang, "Piston dynamic characteristics analyses based on FEM method Part I: Effected by piston skirt parameters," Advances in Engineering Software, vol. 75, pp. 68-85, 2014.

[20] B. Zhao, X.-D. Dai, Z.-N. Zhang, and Y.-B. Xie, "A new numerical method for piston dynamics and lubrication analysis," Tribology International, vol. 94, pp. 395-408, 2016.

[21] Z. Zhang, Y. Xie, X. Zhang, and X. Meng, "Analysis of piston secondary motion considering the variation in the system inertia," Proceedings of the Institution of Mechanical Engineers, Part D: Journal of Automobile Engineering, vol. 223, no. 4, pp. 549-563, 2009.

[22] X. Meng and Y. Xie, "A new numerical analysis for piston skirtliner system lubrication considering the effects of connecting rod inertia," Tribology International, vol. 47, pp. 235-243, 2012.

[23] X. Meng, L. Ning, Y. Xie, and V. W. Wong, "Effects of the connecting-rod-related design parameters on the piston dynamics and the skirt-liner lubrication," Proceedings of the Institution of Mechanical Engineers, Part D: Journal of Automobile Engineering, vol. 227, no. 6, pp. 885-898, 2013.

[24] X. Meng, C. Fang, and Y. Xie, “Transient tribodynamic model of piston skirt-liner systems with variable speed effects," Tribology International, vol. 94, pp. 640-651, 2016.

[25] J.-C. Zhu, H.-H. Zhu, S.-D. Fan, L.-J. Xue, and Y.-F. Li, "A study on the influence of oil film lubrication to the strength of engine connecting rod components," Engineering Failure Analysis, vol. 63, pp. 94-105, 2016.

[26] M. Pelosi and M. Ivantysynova, "Heat transfer and thermal elastic deformation analysis on the Piston/Cylinder interface of axial piston machines," Journal of Tribology, vol. 134, no. 4, Article ID 041101, 2012.

[27] L. Ning, X. Meng, and Y. Xie, "Incorporation of deformation in a lubrication analysis for automotive piston skirt-liner system," Proceedings of the Institution of Mechanical Engineers, Part J: Journal of Engineering Tribology, vol. 227, no. 6, pp. 654-670, 2013.

[28] B. Jacoboson and L. Floberg, "The finite journal bearing considering vaporization," Chalmers Tekniska Hogskolas Handlingar, vol. 190, p. 72, 1957.

[29] K. O. Olsson, "Cavitation in dynamically loaded bearing," Transactions of Chalmers University of Technology, vol. 308, p. 60, 1965.

[30] Y. Zhao, C. Wei, S. Yuan, and J. Hu, “Theoretical and experimental study of cavitation effects on the dynamic characteristic of spiral-groove rotary seals (SGRSs)," Tribology Letters, vol. 64, no. 3, article no. 50, 2016.

[31] S. Kango, R. K. Sharma, and R. K. Pandey, "Thermal analysis of microtextured journal bearing using non-Newtonian rheology of lubricant and JFO boundary conditions," Tribology International, vol. 69, pp. 19-29, 2014.
[32] C. Liu, Y.-J. Lu, Y.-F. Zhang, S. Li, and N. Müller, "Numerical study on the lubrication performance of compression ringcylinder liner system with spherical dimples," PLoS ONE, vol. 12, no. 7, Article ID e0181574, 2017.

[33] N. Patir and H. S. Cheng, "An average flow model for determining effects of three-dimensional roughness on partial hydrodynamic lubrication," Transactions of the ASME, vol. 100, no. 1, pp. 12-17, 1978.

[34] N. Patir and H. S. Cheng, "Application of average flow model to lubrication between rough sliding surfaces," Journal of Tribology, vol. 101, no. 2, pp. 220-230, 1979.

[35] C. Wu and L. Zheng, "Average Reynolds equation for partial film lubrication with a contact factor," Journal of Tribology, vol. 111, no. 1, pp. 188-191, 1989.

[36] Q. Yang and T. G. Keith, "Two-dimensional piston ring lubrication-part i: rigid ring and liner solution," Tribology Transactions, vol. 39, no. 4, pp. 757-768, 1996.

[37] D. Zhu, H. Cheng, T. Arai, and K. Hamai, "Numerical analysis for piston skirts in mixed lubrication. Part I: Basic modeling," Journal of Tribology, vol. 114, no. 3, pp. 553-562, 1992.

[38] B. Yin, X. Li, Y. Fu, and W. Yun, "Effect of laser textured dimples on the lubrication performance of cylinder liner in diesel engine," Lubrication Science, vol. 24, no. 7, pp. 293-312, 2012.

[39] J. A. Greenwood and J. H. Tripp, "The contact of two nominally flat rough surfaces," Proceedings of the Institution of Mechanical Engineers, vol. 185, no. 1, pp. 625-633, 2016. 


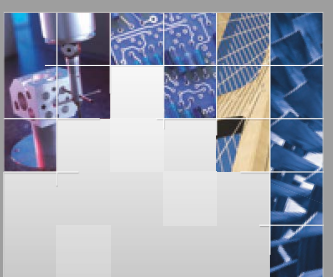

\section{Enfincering}
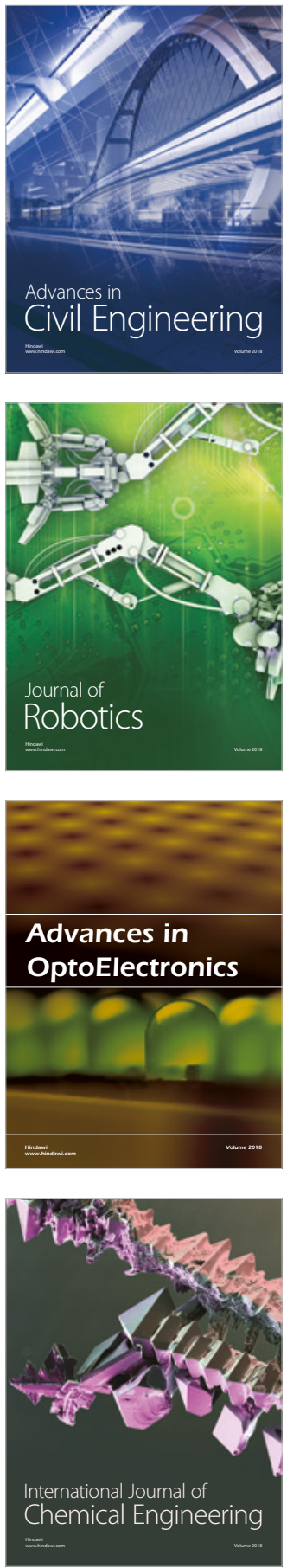

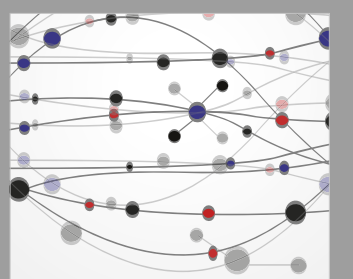

\section{Rotating \\ Machinery}

The Scientific World Journal

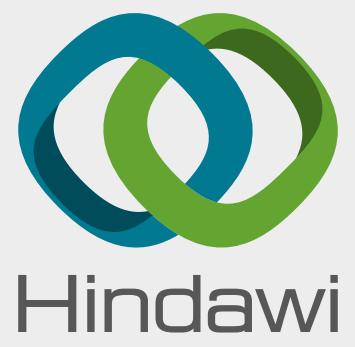

Submit your manuscripts at

www.hindawi.com
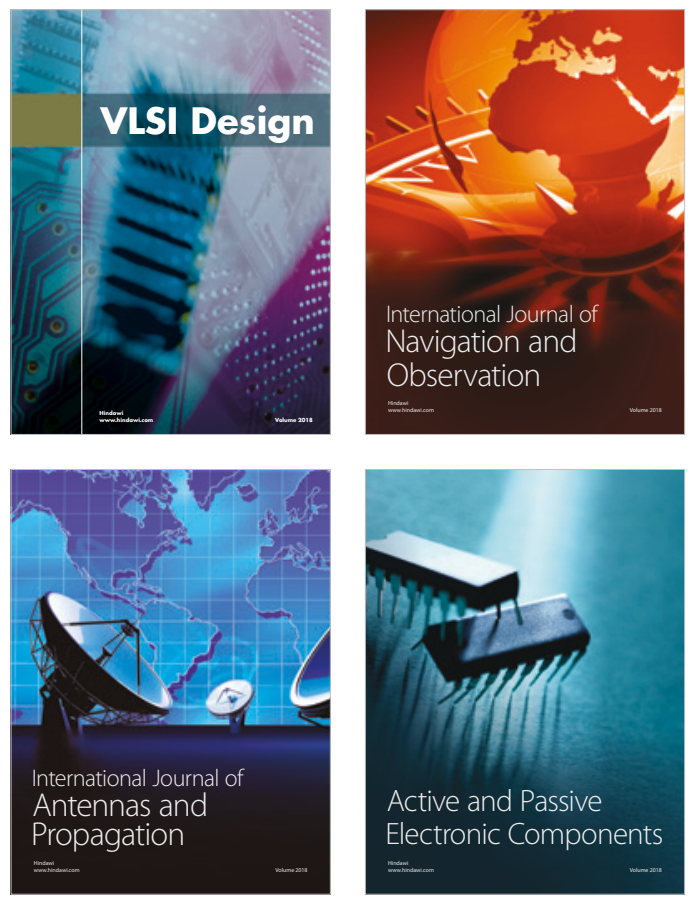
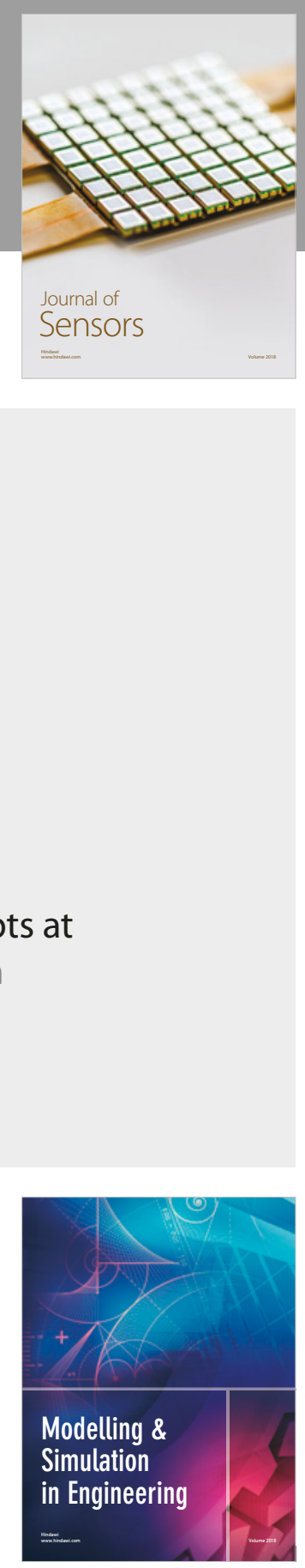

\section{Advances \\ Multimedia}
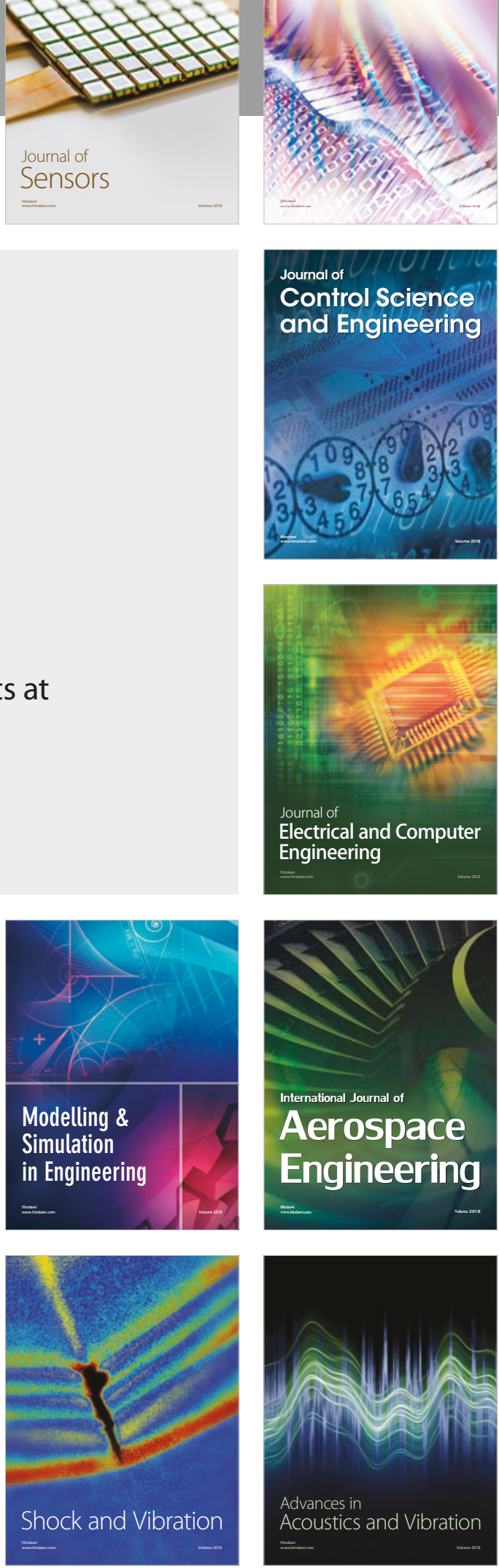